\title{
XXIII. Über das Krystallisationsschema der Chloride, Bromide, Jodide von Natrium, Kalium und Magnesium, sowie über das Vorkommen des Broms und das Fehlen von Jod in den Kalisalzlagerstätten.
}

\author{
Von
}

H. E. Boeke in Künigsberg i. Pr.

(Mit 13 Textliguren.)

\section{Einleitung.}

Bekanntlich wird der Brombedarf der Industrie in Europa ${ }^{\text {) }}$ gedeckt aus den Endlaugen, welche bei der Verarbeitung der carnallitischen Kalisalze gewonnen werden. Nach Kubierschky ${ }^{2}$ ) enthält das Rohcarnallit genannte natürliche Salzgemisch 0,15 bis $0,25 \% B r$, das Carnallitmineral 0,25 bis $0,42 \%$. Allgemein wird angenommen, daß das Brom als isomorphe Vertretung des Chlors im Carnallit und ebenso im Bischofit und Tachhydrit vorhanden ist. Nach den angegebenen Zahlen würdeñ also auf $100 \mathrm{Mol}$. Chlor in dem Mineral Carnallit 0,3 bis 0,5 Mol. Brom vorkommen. Auch für den Bischofit $\mathrm{MgCl}_{2} .6 \mathrm{H}_{2} \mathrm{O}$ der Kalisalzlagerstätten wird ein relativ hoher Bromgehalt $(0,5 \%)$ angegeben $\left.{ }^{3}\right)$. Zahlen über den mittleren Bromgehalt von Tachhydrit $2 \mathrm{MgCl}_{2}, \mathrm{CaCl}_{2} \cdot 12 \mathrm{H}_{2} \mathrm{O}$ sind mir nicht bekannt.

Die nicht magnesiumhaltigen Chlorsalze der Lagerstälten dagegen, Steinsalz, Sylvin und weiterhin auch Kainit $\mathrm{MgSO}_{4} \cdot \mathrm{KCl} \cdot 3 \mathrm{H}_{2} \mathrm{O}$ kämen nach den bisherigen Ansichten in bezug auf Bromgehalt den ersteren gegenüber nicht in Betracht. Andererseits ist die Mischkrystallbildung von $\mathrm{KCl}$ und $\mathrm{KBr}$ von $\mathrm{Fock}^{4}$ ) nachgewiesen. Über isomorphe Vertretung von Chlor durch Brom im aus wässeriger Iösung gebildeten Steinsalze und im Kainit sind keine Untersuchungen veröffentlicht.

1) In Amerika wird Brom aus den Mutterlaugen der Kochsalzgewinnung abgeschieden (Muspratt's Handbuch d. Techn. Chemie 1888, 1, 2004).

2) Die Deutsche Kaliindustrie, 1907, 60.

3) Vergl. E. Erdmann in Deutschlands Kalibergbau 1907, 9.

4) Diese Zeitschr. 1897, 28, 358-362. 
Über d. Krystallisationsschema d. Chloride, Bromide, Jodide v. Natrium usw. 347

Zur leichteren Übersicht der vorliegenden Abhandlung ist die Reihenfolge der Abschnitte nachfolgend zusammengestellt.

A. Synthetischer Teil S. 347 .

I. Untersuchungsmethoden S. 347. a) Darstellung der Krystalle. b) Lüslichkeitshestimmungen. c) Analytische Methoden.

II. Gleichgewichtsdiagramm der Salze und Lüsungen, bestehend aus $\mathrm{K}, \mathrm{Mg}, \mathrm{Cl}, \mathrm{Br}$ mit Wasser bei $25^{0} \mathrm{~S}$. 351. a) $\mathrm{KCl}-\mathrm{MgCl}_{2}-\mathrm{H}_{2} \mathrm{O}$. b) $\mathrm{KBr}-\mathrm{MgBr}_{2}-\mathrm{H}_{2} \mathrm{O}$. c) $\mathrm{MgCl}_{2}-\mathrm{MgBr}_{2}-\mathrm{I}_{2} \mathrm{O}$. d) $\mathrm{KCl}-\mathrm{KBr}-\mathrm{II}_{2} \mathrm{O}$. e) Carnallit-Bromcarnallit. f) Dic mit Carnallit-, bezw. Bromcarnallitmischkrystallen im Gleichgewichte stehenden Mischkry-. stalle von Kaliumchlorid und -bromid. g) Vollständiges Gleichgewichtsdiagramm des Systemes $\mathrm{K}, \mathbf{M g}, \mathrm{Cl}, \mathrm{Br}, \mathrm{H}_{2} \mathrm{O}$ bei $25^{0}$.

III. Das System $\mathrm{NaCl}-\mathrm{NaBr}-\mathrm{H}_{2} \mathrm{O}$ S. 360 .

IV. Krystallisation der Iösungen von $K, M g, C l$ mit kleinem Bromgehalt unter gleichzeitiger Sälligung an Chlornatrium S. 363. a) Chlorkalium und $\mathrm{NaCl}$. b) Carnallit und $\mathrm{NaCl}$.

V. Tachhydrit und Kainit S. 364 .

VI. Einfluß der Temperatur auf die Gleichgewichte bei kleinem Bromgehalt der Iüsung S. 365.

B. Anwendungen auf das natürliche Vorkommen S. 366 .

I. Schlußfolgerungen aus dem synthetischen Teil S. 366 .

II. Analytische Methode der Bestimmung von Bromid neben stark überwiegendem Chlorid, sowie über die Bestimmung von Carnallit S. 367 .

III. Chemisches Profil der Salzablagerung von der Anhydritregion bis zum Salzton im Berlepsch-Bergwerk, Staßfurt S. 369.

IV. Chemische Profile durch Salzablagerungen von Salzdetfurth S. 373.

V. Die van't $H$ offschen Versuchsergebnisse im Vergleich mit den natürlichen Vorkommnissen S. 374.

VI. Überblick über den Bromgehalt der Norddeutschen Kalisalze S. 382 .

C. Über das Fehlen von Jod in den Kalisalzen S. 388.

\section{A. Synthetischer Teil.}

I. Untersuchungmethoden.

a) Darstellung der Krystalle. Die in Frage kommenden Mischkrystalle wurden gezüchtet, indem einige hundert Gramme der entsprechenden Lösungen ${ }^{1}$ ) der langsamen Verdunstung ausgesetzt wurden. Dic Lösungen

1) Alle benutzten Materialien waren von Merck pro analysi bezogen. 
befanden sich über Chlorcalcium, resp. Schwefelsäure in einem teilweise evacuierten Exsiccator, welcher in einem Thermostaten bei $25^{\circ}$ gehalten wurde. Die successive Krystallabscheidung wurde unter dem Polarisationsmikroskope verfolgt. War eine zur Analyse genügende Menge (ca. 1,5 g) Krystalle ausgeschieden, so wurde die Zusammensetzung von Lösung und Krystallen analytisch bestimmt.

Eine schon von vielen empfundene Schwierigkeit ist die Trennung von Krystallen und anhängender Mutterlauge.

Gewöhnlich wird Absaugen dor Krystalle auf dom Saugetrichter und Abpressen zwischen Fillrierpapier angegeben 1 ). Diese Methode versagt aber, wenn die Krystalle an der Luft verderben, z. B. sehr hygroskopisch sind, wie es bei den Mischkrystallen von $\mathrm{MgCl}_{2} .6 \mathrm{H}_{2} \mathrm{O}$ und $\mathrm{MgBr}_{2} .6 \mathrm{H}_{2} \mathrm{O}$ der Fall ist. Es zeigte sich, daß sie bei dem Abpressen mehr Feuchtigkeit aus der Iult aufnehmen, als sie an das Filtrierpapier abgeben. Überdies ist die Multerlauge bei derartig löslichen Salzen so viskös, daß nach dem Absaugen häufig ca. ein Viertel der abgesonderten Masse aus Mutterlauge besteht2). Von van Bijler(3) ist deshalb eine indirecte Methode zur Bestimmung der Quantital anhängender Mutterlauge angegeben, welche vielfach befolgt wird. Er setzt eine bekannte Menge einer indifferenten Substanz zur Lösung hinzu und bestimmt den Gehalt der feuchten Krystallmasse an dieser Substanz. Eine einfache Proportionalitätsrechnung gibt dann die Menge der anhaftenden Mutterlauge. Diese Methode hat aber viele Mißlichkeiten: 1. ist es in den meisten Fällen fraglich, ob die hinzugefügte Substanz wirklich indifferent ist, $d . h$. das Gleichgewicht nicht verschieb(4); 2. muß die Menge Indicator klein sein, dadurch vergrößert sich aber der Analysenfehler stark bei der Berechnung; 3. möchte ich darauf hinweisen, daß der Methode ein theoretischer Fehler anhaftet. Die anhängende Mutterlauge befindel sich nämlich in einer adsorbierten Schicht, und in dieser wird der Gehalt an gelöster Substanz nicht übereinstimmen mit demjenigen in der Hauptmenge der Lauge, es muß eine Art Verteilungserscheinung auftreten. Die Proportionalitätsrechnung ist also principiell nicht berechligt, und der hinzukommende Factor bleibl im allgemeinen unbekannt. Ein Beispiel möge das Gewicht des oben genannten Einwandes erläulern. Nehmen wir kubische Krystalle an von $0,2 \times 0,2 \times 0,2 \mathrm{~mm}$; zur Schatzung der Dicke einer adsorbierten Schicht benutzen wir Magnus' Zahl von $8 \mu$ für die Adsorption von Schwefeldioxyd auf Glas 5 ; setzen wir die specifischen Gewichte von Krystall und Lauge gleich, dann ist also:

$$
\frac{\text { Gewicht adsorbierte Mutterlauge }}{\text { Gewicht Krystalle }}=\mathbf{0 , 2 4} \text {, }
$$

so daß auf $1 \mathrm{~g}$ Krystalle nach dieser Schätzung $0,24 \mathrm{~g}$ Lauge adsorbierl sein würde. Also kann der Einfluß dieser capillaren Adsorption unter Umständen deutlich ins Gewicht fallen.

In der vorliegenden Untersuchung wurde die anhaftende Mutterlauge auf verschiedene Weise entfernt, resp. in Rechnung gebracht, je nach der

1) Z. B. Bakhuis Roozebo om $\mathrm{KClO}_{3}-\mathrm{TlClO}_{3}$. Zeitschr. f. phys. Chemie 1891, 8, 532. Ausz. diese Zeitschr. 22, 602.

2) Vergl. Feit, Journ. f. prakt. Ch. n. F. 1891, 39, 373.

3) Zeitschr. f. phys. Chemie 1891, 8, 343-366.

4) Eine solche Gleichgewichtsverschiebung erwähnt van Merum-Terwogt. Br

- J. Zeitschr. f. phys. Chemie 1905, 47, 214.

i) Ost wald, Lebrb. d. Allg. Ch. II2, 387. 
Art der betreffenden Salze. Nicht hygroskopische und weniger lösliche Salze, wie Mischkrystalle von $K C l$ und $K B r$, wurden in einigen Fällen durch Absaugen und Abpressen zwischen Filtrierpapier rein erhalten, aber häufiger und - meiner Meinung nach — besser durch feines Pulverisieren und Auswaschen während des Absaugens mittels einiger Tropfen Wasser. Bei der kurzen Berührung von Iı̈sungsmittel und Krystallen wird wohl eine gesättigte Lüsung nicht entstehen künnen, es wird sich nur eine dünne äußere Schicht der Mischkrystalle auflösen, wodurch eine Änderung in der Zusammensetzung der Mischkrystalle nicht eintreten kann; die ursprüngliche Mutterlauge wird aber vollständig entfernt. Nach dem Auswaschen wurde bei $130^{\circ}$ bis $140^{\circ}$ getrocknet. Insbesondere ist diese Methode zu empfehlen, wenn es sich darum handelt, zu entscheiden, ob eine Componente der Lösung in den Krystallen überhaupt in isomorpher Mischung auftritt, da es ja in dem Falle ganz besonders darauf ankommt, die letzte Spur der Mutterlauge zu entfernen. Ein weiterer Vorteil der Auswaschmethode gegenüber dem $\Lambda$ bpressen bestelıt darin, daß man die Krystalle viel mehr zerkleinern und so eventuelle Einschlüsse beseitigen kann.

Für die sehr hygroskopischen Salze mußte, wie gesagt, ein anderes Verfahren angewendet werden. Die Krystalle wurden von der Mutterlauge so weit wie möglich getrennt durch Ausschleudern in einer Handzentrifuge, welche 10000 Drehungen in der Minute machte. Die Menge anhaftender Mutterlauge blieb nach diesem Verfahren in den meisten Fällen unter $10 \% 1$ ). Diese Menge war aus den Analysendaten der $\mathrm{Cl}$ - und $\mathrm{Br}$-Bestimmungen durch Berechnung festzustellen. Diese Berechnung selzt voraus, daß die stöchiometrische Formel der Mischkrystalle bekannt ist, und läßt den dritten der gegen die van Bijlertsche Methode eingebrachten Einwände (die Nichlberücksichtigung der capillaren Adsorption) bestehen.

Als concretes Beispiel für die Berechnung sei ein bestimmter Mischkrystall $\mathrm{Mg}(\mathrm{Cl}, \mathrm{Br})_{2} .6 \mathrm{H}_{2} \mathrm{O}$ genommen. Auf $100 \mathrm{~g}$ der analysierten Mischkrystalle + anhaftenden Mutterlauge sind:

$$
\begin{aligned}
x \text { g Krystalle } \\
100-x g \text { Lauge. }
\end{aligned}
$$

Es sind :

in der Lauge auf

in den Krystallen auf

$100 \mathrm{~g} k \mathrm{~g} \mathrm{Cl}$

$l \mathrm{~g} \mathrm{Br}$,

$100 \mathrm{~g} y \mathrm{~g} C l$

$\approx \mathrm{g} B r$

in der feuchten Krystallmasse auf $100 \mathrm{~g} \mathrm{~m} \mathrm{~g} \mathrm{Cl}$

$n$ g $B r$.

1) Feit (l. c.) bestimmte nach dem Absaugen auf den Saugetrichter beim Bromcarnallit rund $22 \%$ anbängende Mutterlauge. 
Die Mengen $\mathrm{Mg}$ und $\mathrm{H}_{2} \mathrm{O}$ in den Krystallen sind von $y$ und $\approx$ stöchiometrisch abhängig. Setzen wir die durch ein Gramm $\mathrm{Cl}$ bedingte Menge $\mathrm{Mg}+\mathrm{H}_{2} \mathrm{O}$ :

$$
\left.\frac{24,36+6 \cdot 18,02}{2 \cdot 35,45}=A^{1}\right)
$$

ebenso die einem Gramm Brom entsprechende Menge $\mathrm{Mg}+\mathrm{H}_{2} \mathrm{O}$

$$
\left.\frac{24,36+6 \cdot 18,02}{2 \cdot 79,96}=B^{1}\right)
$$

dann besteht die Gleichung:

$$
A y+B z=100-y-\approx .
$$

Für den Chlor- und Bromgehalt des feuchten Krystallmateriales gelten die Gleichungen:

$$
\begin{aligned}
& \frac{x}{100} y+\frac{100-x}{100} k=m \\
& \frac{x}{100} z+\frac{100-x}{100} l=u .
\end{aligned}
$$

Aus diesen drei Gleichungen mit drei Unbekannten kann man $100-x$, also den Prozentgehalt anhaftender Mutterlauge in der analysierten Krystallmasse, berechnen:

$$
100-x=100 \begin{aligned}
& 100-(A+1) m-(B+1) n \\
& 100-(A+1) k-(B+1) l
\end{aligned} .
$$

$A$ us den Gleichungen (2) und (3) ergeben sich $y$ und $z$, und damit ist die wirkliche Zusammensetzung der Mischkrystalle bekannt.

b) Die Lüslichkeitsbestimmungen. Wo nur die Zusammensetzung der Lösung, welche mit einem Bodenkörper oder mehreren im Gleichgewichte ist, festzustellen war und nicht die Zusammensetzung dieser Bodenkörper selbst, wurden Löslichkeitsbestimmungen ausgeführt nach dem von No yes ${ }^{2}$ ) angegebenen Verfahren (bei dem ein im Wasserbade von bestimmter Temperatur rotierendes Rad benutzt wird, auf welchem köhrchen mit den zu untersuchenden Körpern befestigt sind).

c) Analytische Methoden. In bezug auf die Analysen kam in erster Linie die quantitative Bestimmung von $B r$ und $J$ neben $C l$ in Betrachl. Hierzu wurde die Methode von Friedheim und Meyer ${ }^{3}$ ) gewählt; sie haben die zahlreichen Methoden zur Lösung der genannten Aufgabe zusammengestellt und untersucht, und nach eingehender Prüfung das beste und einfachste Verfahren combiniert. Aus der gemischten Lüsung von

1) Die Zahlen in der Gleichung sind die Molekulargewichte von $\mathrm{Mg}, \mathrm{H}_{2} \mathrm{O}, \mathrm{Cl}$ und $\mathrm{Br}$.

2) Zeitschr. f. phys. Chemie 1892, 9, 606.

3) Zeitschr. f. anorg. Chemie 1892, 1, 407. 
Chlorid, Bromid und Jodid wird nur das Jod (quantitativ) freigemachl mittels Kaliumarseniat und Schwefelsäure. Es wird überdestilliert, in $K J$ Lösung aufgefangen und mit Thiosulfat titriert. Aus der Lösung von Chlorid und Bromid wird das $B r$ ebenfalls für sich quantitativ ausgeschieden durch Kaliumbichromat und Schwefelsäure und nach dem Auffangen in $K J$-Lösung titriert. Das Chlorid kann im Hückstande gravimetrisch bestimmt werden, ich habe es aber vorgezogen - weil jedesmal nur $C l$ neben $\mathrm{Br}$ oder $\mathrm{Cl}$ neben $J$ zu bestimmen war - , die beiden Halogene zusammen mit Silbernitrat zu titrieren. Diese Titration wurde nach $M o h r$ ausgeführt, wenn nur Alkalihalogenid zu bestimmen war. Die Mohrsche Methode zeigte sich aber als weniger genau, wenn sich auch $M g$ in der Lösung befand - wahrscheinlich wegen einer spurenweisen Zersetzung von $\mathbf{M g}$ Halogenid während der Mischkrystallzüchtung - . In letzterem Falle wurde immer das Volhardsche Verfahren angewandt. Die Methode von Friedheim und Meyer lieferte bei den Kontrollbestimmungen mit bekannten Quantiläten Bromid und Jodid sehr gute Resultate. Nur zeigle es sich vorteilhaft, die Vorlage mit dem Ableitungsrohre des Destillationskolbens durch einen Kautschukstopfen fest zu verbinden, um einer Verdunstung des Halogens vorzubeugen.

Die Bestimmung der sehr kleinen Brommengen in den nalürlichen Salzgemischen wird in dem entsprechenden Abschnille besprochen werden.

IJie Maguesiabestimmungen wurden nach der gewöhnlichen Methode von Gibbs durch Wïgung als $M_{g_{2}} P_{2} O_{7}$ ausgeführt. Für Kalifeststellungen neben Magnesia habe ich nicht die directe Methode gewählt, welche z. I3. Lüwenherz') angibt, sondern einer indirecten Melhude den Vorzug gegeben, nämlich der Wägung von $K$ und $M g$ zusammen als Sulfat und die Einzelbestimmung von $M I y$. Kalium kommt in den Iösungen, welche Callnallit oder Bromcarnallit als Bodenkörper enthalten, in bezug auf $M g$ nur in kleiner Menge vor, aber gerade dann sind die beiden einfachen und fehlerfreien Operationen der Sulfat- und gesonderten $\mathbf{M g}$-Bestimmung exacter als eine directe 'Trennung und Bestimmung von Kalium.

II. Gleichgewichtsdiagramm der Salze und Lösungen, bestehend aus $K, M g, C l$ und $B r$ mit Wasser bei $\mathbf{2 5}^{\circ}$.

a) $\mathrm{KCl}-\mathrm{MgCl}_{2}-\mathrm{H}_{2} \mathrm{O}$. Das Diagramm bei 250 ist aus den Untersuchungen von van' $t$ Hoff und Meyerhoffer ${ }^{2}$ ) bekannt. Es trilt dabei ein Doppelsalz auf, der rhombische, pseudohexagonale Ciarnallit $\mathrm{MgCl}_{2}$. $\mathrm{KCl} .6 \mathrm{II}_{2} \mathrm{O}$.

1) Zeitschr. f. phys. Chemie 1894, 13, 475. Ausz. dicse Zeilschr. 26, 637. 32, 88.

2) Silzungsber. cl. k. pr. Akad. J. Wiss. 1897, 487-507. Ausz. diese Zeitsclur. 
b) $\mathrm{KBr}-\mathrm{MgBr}_{2}-\mathrm{H}_{2} \mathrm{O}$ bildet ebenfalls ein Doppelsalz $\mathrm{MgBr}_{2} . \mathrm{KBr} \cdot 6 \mathrm{H}_{2} \mathrm{O}$, das von $\mathrm{Feit}^{1}{ }^{1}$ dargestellt und analysiert wurde. Später hat de Schulten ${ }^{2}$ ) dasselbe Doppelsalz erhalten, analysiert und krystallographisch untersucht. Die Krystalltracht unterscheidet sich recht deutlich von derjenigen des Carnallits; während der letztere vielflächige, hexagonal aussehende Krystalle bildet, ist Bromcarnallit nach de Schulten zwar auch rhombisch, zeigt aber immer nur die Basis und ein Prisma. Die Winkelverhältnisse beim Carnallit und Bromcarnallit sind gänzlich verschieden ${ }^{\%}$ ).

Von Löwig4) wurde ein anderes Doppelsalz, $\mathrm{MgBr}_{2} .2 \mathrm{KBr} \cdot 6 \mathrm{H}_{2} \mathrm{O}$ beschrieben, das aber von $F$ it nicht erhalten werden konnte. Systematische Untersuchungen bei bestimmter Temperatur sind allerdings von Feit nicht angestellt worden. Ich habe deshalb eine Lösung von ca. 3 Molekülen $\mathrm{MgBr}_{2}$ auf $1 \mathrm{Mol} . \mathrm{KBr}$ bei $25^{\circ}$ der Verdunstung überlassen. Zuerst schied sich reichlich $\mathrm{KBr}$ aus, darauf eine doppelbrechende Krystallart, welche das ausgesonderte $\mathrm{KBr}$. allmählich aufzehrle. Jetzt wurde das feste Salz abfiltriert und das Filtrat weiter eingeengt. Die weitere Ausscheidung bestand nur aus Krystallen ${ }^{5}$ ), welche mit den von de Schulten beschriebenen optisch übereinstimmten. Der Bromgehalt dieser Krystalle stimmte auf die Formel $\mathrm{MgBr}_{2} . \mathrm{KBr} \cdot 6 \mathrm{H}_{2} \mathrm{O}$, wie sie auch de Schulten nachgewiesen hat. Bei fortschreitender Verdunstung traten schließlich große, monokline Krystalle von $\mathrm{MgBr}_{2} .6 \mathrm{H}_{2} \mathrm{O}$ auf, und beide Krystallarten vermehrten sich, bis alle Flüssigkeit verschwunden war.

Diesen Versuchsergebnissen zufolge stimmt das Lüslichkeitsschema für $\mathrm{KBr}, \mathrm{MgBr}_{2}$ und Wasser in seiner allgemeinen Art überein mit demjenigen für die entsprechenden Chloride, und ein Doppelsalz $\mathrm{MgBr}_{2} \cdot 2 \mathrm{KBr} \cdot 6 \mathrm{H}_{2} \mathrm{O}$ tritt bei $25^{\circ}$ nicht auf.

Zur Feststellung des Diagramms wurden Löslichkeitsbestimmungen bei $25^{\circ}$ ausgeführt, welche in der nachfolgenden Tabelle vereinigt sind:

1) Journ. f. prakt. Chemie 1889 , n. F. 89, 373.

2) Bull. Soc. Chimie 1897, 17, 167. Ausz. diese Zeitschr. B1, 179.

3) Vergl. Grolh, Chemische Krystallographie 1906, 1, 376 u. 377. Die Ergebnisse einer näheren krystallographischen Untersuchung gedenke ich in einer besonderen Abhandlung zu veröffentlichen.

4) Rep. Pharm. (Buchner) 29, 261.

5) Die von Feit erwähnte Schwierigkeit, daß er nie das Doppelsalz ganz frei von $K B r$ erhalten konnte, läßt sich also in dieser Weise beseitigen. 
Über d. Krystallisationsschema d. Chloride, Bromide, Jodide v. Natrium usw. 353

\begin{tabular}{|c|c|c|c|c|c|c|c|c|}
\hline \multirow{2}{*}{ Sättigung an } & \multicolumn{3}{|c|}{ Gehalt in Gew.-Proc. } & \multicolumn{3}{|c|}{ Mol a. $100 \mathrm{~g}$ Lösung } & \multicolumn{2}{|c|}{$\mathrm{Mol} \mathrm{a.} 1000 \mathrm{Mol} \mathrm{H}_{2} \mathrm{O}$} \\
\hline & $B r$ & $M g$ & $K$ & $\mathrm{Br} r_{2}$ & $M g$ & $K_{2}$ & $\mathrm{MgBr}_{2}$ & $K B r$ \\
\hline $\mathrm{MgBr}_{2} .6 \mathrm{H}_{2} \mathrm{O}$ Mittel & 43,66 & 6,66 & & 0,2731 & 0,2736 & & 99,1 & \\
\hline $\begin{array}{r}\mathrm{MgBr}_{2} .6 \mathrm{H}_{2} \mathrm{O} \text { u. } \\
\text { Bromcarnallit } \\
\text { Mittel } \\
2 .\end{array}$ & $\begin{array}{l}43,44 \\
43,59 \\
43,52\end{array}$ & $\begin{array}{l}\mathbf{6 , 6 9} \\
6,70 \\
6,70\end{array}$ & $\begin{array}{l}0,02 \\
0,05 \\
0,04\end{array}$ & 0,272 & 0,275 & 0,001 & 99,0 & 0,4 \\
\hline $\begin{array}{cc}\text { Bromcarnallit } & 1 . \\
\text { II. } K B r & 2 . \\
& \text { Mittel }\end{array}$ & $\begin{array}{l}39,34 \\
39,60 \\
39,47\end{array}$ & $\begin{array}{l}\mathbf{5 , 6 7} \\
\mathbf{5 , 7 6} \\
\mathbf{5 , 7 2}\end{array}$ & $\begin{array}{l}1,03 \\
1,00 \\
1,02\end{array}$ & $0,2 / 7$ & 0,235 & 0,013 & 78,6 & 8,7 \\
\hline Mittel & 27,38 & & & & & & & 104,2 \\
\hline
\end{tabular}

Löslichkeitsbestimmungen von $\mathrm{MgBr}_{2} .6 \mathrm{II}_{2} \mathrm{O}$ bei verschiedenen Temperaturen sind vor kurzem von B. Menschutkin') ausgeführt. Die von mir gefundene Zahl stimmt mit der aus den Angaben von Menschutkin für $25^{\circ}$ extrapolierten $(42,95 \% \mathrm{Br})$ genügend überein.

Über die Löslichkeit von $K B r$ liegen nur ältere Bestimmungen von de Coppet ${ }^{2}$ ) vor. Die lineare Extrapolierung für $25^{\circ}$ aus seinen Zahlen für $20^{\circ}$ und $40^{\circ}$ ergibt $68 \mathrm{~g}$ $K B r$ auf $100 \mathrm{~g}$ Wasser, während meine Bestimmung $68,87 \mathrm{~g} K B r$ auf 100 g Wasser liefert, also befriedigend damit übereinstimmt.

Aus den Daten der Tabelle ergibt sich das Gleichgewichtsdiagramm der Fig. 1. Zum Vergleich ist das Diagramm von $\mathrm{MgCl}_{2}-\mathrm{KCl}-\mathrm{H}_{2} \mathrm{O}$ punktiert daneben gezeichnet. Zwischen den Concentrationen, welche durch $A$ und $E$ angegeben sind, scheidet sich zuerst $K B r$ aus; $E$ ist der Umwandlungspunkt $\mathrm{KBr} \longrightarrow$ Bromcarnallit. Zwischen $E$ und $F$ bildet Bromcarnallit

Fig. 1.

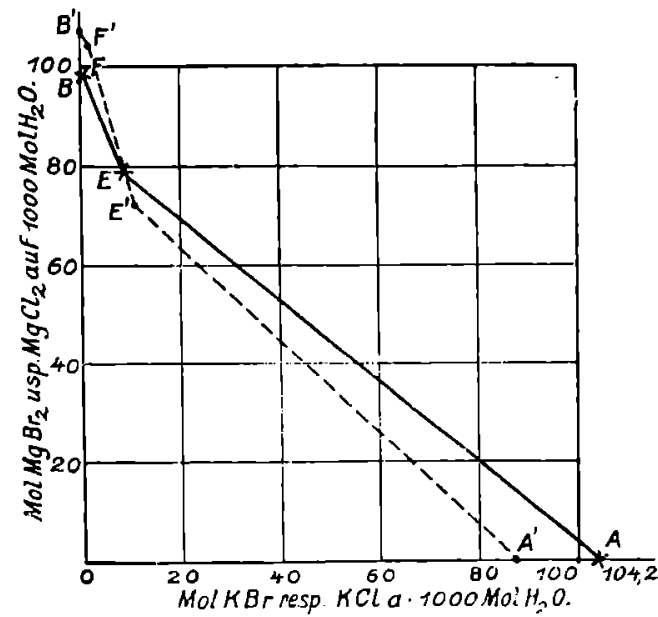

Gleichgewichtsdiagramm $\mathrm{KBr}-\mathrm{MgBr}_{2}-\mathrm{H}_{2} \mathrm{O}$ bei 250 . die erste Ausscheidung, während die kurze Linie $B F$ die Erstausscheidung von $\mathrm{MgBr}_{2} \cdot 6 \mathrm{H}_{2} \mathrm{O}$ darstellt. $\mathrm{F}$ ist als Krystallisationsendpunkt für Bromcarnallit $+\mathrm{MgBr}_{2} .6 \mathrm{H}_{2} \mathrm{O}$ aufzufassen. Die Lage von $F^{\prime}$ ganz nahe an der Ordinatenaxe

1) Zeitschr. I. anorg. Chem. 1907, 52, 152.

2) Ann. chim. phys. $1883,[5], 30,416$.

Groth, Zeitschrift f. hrystallogr. XIV. 
zeigt, daß eine an $\mathrm{MgBr}_{2} \cdot 6 \mathrm{H}_{2} \mathrm{O}$ gesättigte Lüsung nur eine sehr geringe Menge Kalium aufzulösen imstande ist.

c) $\mathrm{MgCl}_{2}-\mathrm{MgBr}_{2}-\mathrm{H}_{2} \mathrm{O}$. Über die Krystalle, welche sich aus gemischten Lösungen von $\mathrm{MgCl}_{2}$ und $\mathrm{MgBr}_{2}$ ausscheiden, liegen keine Bestimmungen vor. Es ist lediglich bekannt, daß die beiden Componenten für sich bei gewöhnlicher Temperatur als Hexahydrat auskrystallisieren $\left(\mathrm{MgCl}_{2} .6 \mathrm{H}_{2} \mathrm{O}\right.$ bis 11701$), \mathrm{MgBr}_{2} .6 \mathrm{II}_{2} \mathrm{O}$ bis zu seinem Schmelzpunkt 16402$)$ ). $\mathrm{MgCl}_{2} .6 \mathrm{H}_{2} \mathrm{O}$ besitzt monokline Krystallform $\left.{ }^{3}\right) . \mathrm{MgBr}_{2} .6 \mathrm{HI}_{2} \mathrm{O}$ ist nicht gemessen worden wegen der starken Zerfließlichkeit; van ' $t H$ off und Dawson ${ }^{4}$ ) erwähnen die $\mathrm{A} h n l i c h k e i t$ mit $\mathrm{MgCl}_{2} .6 \mathrm{H}_{2} \mathrm{O}$ und die Fühigkeit der Mischkrystallbildung mit dern letzteren.

Aus den Analysen der gemischten Lösungen von $\mathrm{MgCl}_{2}, 6 \mathrm{H}_{2} \mathrm{O}$ und $\mathrm{MgBr}_{2} .6 \mathrm{H}_{2} \mathrm{O}$ und der auscentrifugierten Krystalle, welche bei $25^{\circ}$ mit diesen Lösungen im Gleichgewichte sind, ergab sich eine stetige Änderung des Verhältnisses von $\mathrm{Cl}$ und $\mathrm{Br}$ in der Lüsung und in den Krystallen. Auch die optische Untersuchung steht mit der Annahme, dab eine discontinuierliche Änderung des Bodenkürpers nicht auftritt, im Einklange. Es bilden also $\mathrm{MgCl}_{2} .6 \mathrm{H}_{2} \mathrm{O}$ und $\mathrm{MgBr}_{2} .6 \mathrm{H}_{2} \mathrm{O}$ eine lückenlose Reihe von Mischkrystallen. Weil dadurch der ehemische Typus der Krystalle $\mathrm{Mg}\left(\mathrm{Cl}, \mathrm{Br}_{2}\right)_{2} \cdot 6 \mathrm{H}_{2} \mathrm{O}$ bekannt ist, kann die Correctur für die anhaftenden Mutterlaugen nach der auf S. 350 angegebenen Rechnungsweise angebracht werden.

\begin{tabular}{|c|c|c|c|c|c|c|c|c|c|}
\hline \multirow[t]{2}{*}{$\mathrm{Nr}$. } & \multicolumn{2}{|c|}{$\begin{array}{c}\text { Lösung } \\
\text { Gew.-Proc. }\end{array}$} & \multicolumn{2}{|c|}{$\begin{array}{l}\text { Feuchte Kryst. } \\
\text { Gew.-Proc. }\end{array}$} & \multirow{2}{*}{$\begin{array}{l}\text { Proc. Mutterl. } \\
\text { in d. Kryst. }\end{array}$} & \multicolumn{2}{|c|}{$\begin{array}{l}\text { Rcine Kryst. } \\
\text { Gew.-Proc. }\end{array}$} & \multirow{2}{*}{$C_{L}$} & \multirow{2}{*}{$C_{K r}$} \\
\hline & $B r$ & $C l$ & $B r$ & $C l$ & & $B r$ & $\mathrm{Cl}$ & & \\
\hline 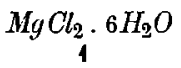 & 4,56 & 23,75 & 3,22 & 31,61 & 14,7 & 2,98 & $\begin{array}{l}\mathbf{3 4 , 8 6} \\
\mathbf{3 2 , 9 6}\end{array}$ & 7.8 & 3.9 \\
\hline$z$ & 8,92 & 21,31 & 7,00 & 29,30 & 13,5 & 6,70 & 30,35 & 15,7 & 8,8 \\
\hline 3 & 13,14 & 18,87 & 11,58 & 26,53 & 12,6 & 11,36 & 27,63 & 23,6 & 15,4 \\
\hline 4 & 17,40 & 16,37 & 17,18 & 23,23 & $\mathbf{9 , 2}$ & 17,15 & 23,92 & 32,0 & 24,1 \\
\hline$\ddot{z}$ & 21,69 & 13,62 & 24, & 18,49 & 13,4 & 24,51 & 19,25 & 41,4 & 36,1 \\
\hline 6 & 25,50 & 11,37 & 32,28 & 13,56 & 10,0 & 33,03 & 13,80 & 49,9 & 51,5 \\
\hline 7 & 30,45 & 8,51 & 39,57 & 9,05 & 8,6 & 40,42 & 9,10 & 61,4 & 66,3 \\
\hline 8 & 33,63 & 6,27 & 45,74 & 5,13 & 8,1 & 46,81 & 8,03 & 70,4 & 80,5 \\
\hline${ }^{9}$ & 38,77 & 3,04 & 50,36 & 2,29 & 6,7 & 51,20 & 2,23 & 85,0 & 91,1 \\
\hline $\mathrm{MgBr}_{2} \cdot 6 \mathrm{H}_{2} \mathrm{O}$ & 43,66 & & & & & 54,65 & & 100 & 100 \\
\hline
\end{tabular}

In der letzten Spalte ist angegeben, in welchem Molekularverhältnisse $\mathrm{Br}$ und $\mathrm{Cl}$, also ebenfalls $\mathrm{MgBr}_{2} \cdot 6 \mathrm{H}_{2} \mathrm{O}$ und $\mathrm{MgCl}_{2} \cdot 6 \mathrm{H}_{2} \mathrm{O}$, in der Lösung und in den Mischkrystallen stehen. Die Molekularprozente $100 \frac{\text { Mol. } B r}{\text { Mol. } B r+\text { Mol. } C l}$

1) van't Hoff und Meyerhoffer, Zeitschr. f. ph. Chem. 1898, 27, 90.

2) B. Menschutkin l. c.

3) Marign a c, Ann. d. Mines 1856, [5], 9, 3.

4) Zeitschr. f. phys. Chem. 1897, 22, 598. 
werden durch $C_{L}$ für die Lösung, durch $C_{K r}$. für die Krystalle gekennzeichnet. Diese Verhältniszahlen sind in Fig. 2 dargestellt. Es ergibt sich aus diesem Diagramm, daß bei ca. $50 \mathrm{Mol}$. $\% \mathrm{Br}$ das Verhältnis der beiden Componenten in der Lüsung und in den Mischkrystallen gleich ist. Dieser Fall ist von Bakhuis Roozeboom in seiner grundlegenden Arbeit über Lüsungen von Mischkrystallen 1) eingehend besprochen. Fine derartige Lösung dampft bei $25^{\circ}$ bis zur Trockne ohne Änderung der Concentration ein.

Aus dem Ergebnisse der lückenlosen Mischkrystallreihe geht hervor, daß $\mathrm{MgBr}_{2}, 6 \mathrm{H}_{2} \mathrm{O}$ mit Bischofit isomorph, also auch mo-

Fig. 2.

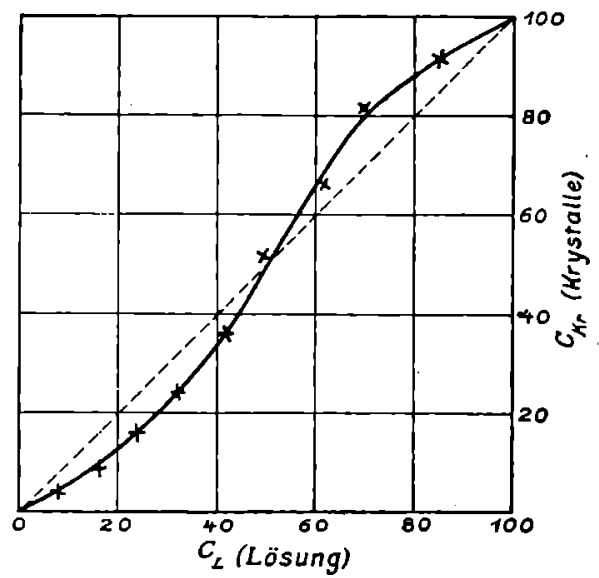

Gleichgewichtsdiagramm $\mathrm{MgCl}_{2}-\mathrm{MgBr}_{2}-\mathrm{H}_{2} \mathrm{O}$. noklin ist. Es sei erwähnt, daß die Mischkrystalle bei allen Zwischenconcentrationen sehr gut ausgebildet waren, während man sonst häufig in der Mitte einer Mischkrystallreihe kleine, verkrüppelte Krystalle antrifft.

d) $\mathrm{KCl}-\mathrm{KBr}-\mathrm{II}_{2} \mathrm{O}$. Dieses Syslem ist von Fock $\left.{ }^{2}\right)$ untersucht worden. Er findet, daß nur Mischkrystalle von 0 bis $92 \mathrm{Mol} .-0 \% \mathrm{KBr}$ müglich sind. In den Lösungen wächst dabei das Molekularverhältnis $\mathrm{KIBr}: \mathrm{KBr}+\mathrm{KCl}$ von 0 bis $86,5 \%$ heran. Aus Lösungen mit weniger als $13,5 \mathrm{Mol} .-0 \% \mathrm{KCl}$ soll reines $K B \%$ sich ausscheiden. Diese kleine, einseitige Mischungslücke hat etwas Befremdendes, was sich noch vermehrt in Anbetracht einer später von Fock ausgeführten Controllbestimmung, nach der eine Lösung mit 12,86 Mol.-0/0 $K(l-$ also in nerhalb der angeblichen Mischungslücke der Bodenkörper - Mischkrystalle mit 8,23 Mol.-0\% $\mathrm{KCl}$ ausscheidet. Nach seinen Mitteilungen auf S. 348 sind die Krystallabscheidungen bei $25^{\circ}$ vorgenommen. Über die Methode der Analyse wird nur berichtet, daß »eine indirecte Methode * benutzt wurde. - Aus meinen Analysen ${ }^{3}$ ) geht hervor, daß die erwähnte Mischungslücke nicht besteht, wie aus den Nr. 9 und 11 in der Tabelle S. 356 und aus der Fig. 3 ersichtlich ist.

1) Zeitsclır. f. phys. Chem. 1894, 8, 522. Ausz. diese Zeitschr. 22, 602.

2) Diese Zeitschr. 1897, 28, 337-413.

3) Auf S. 349 ist erwähnt worden, wie die anbaftende Mutterlauge von den Krystallen vollstándig entfernt wurde. Einer Correctur bedürfen die Krystallanalysen also nicht. 
Es zeigen die Untersuchungen von $\mathrm{Ruff}$ und $\left.\mathrm{Plat} \mathrm{o}^{1}\right)$, daß sich auch aus den trocknen Schmelzen von $\mathrm{KCl}$ und $\mathrm{KBr}$ eine lückenlose Reihe von Mischkrystallen ausscheidet. Eine Wiederholung dieser Versuche bis zu $10 \mathrm{Mol} . \% \mathrm{KCl}$ bestätigte mir, daß keine merkliche Depression des Erstarrungspunktes von $\mathrm{KBr}$ durch den Zusatz von $K C l$ zur Schmelze stattfindet. Diese Tatsache ist nur durch eine Mischkrystallbildung zu erklären. Bei der Abkühlung der Mischkrystalle war auf der Abkühlungscurve keinerlei Anzeichen eines Zerfalles in zwei Phasen zu beobachten, und die erstarrte Masse blieb klar durchsichtig und einheitlich bis zur gewöhnlichen Temperatur ${ }^{2}$ ). Schließlich wurden die so erhaltenen und fein pulverisierten Mischkrystalle mit Wasser bei $25^{\circ} \mathrm{ca}$. 3,5 Stunden geschüttelt und Lösung und Bodenkörper analysiert. Die Ergebnisse sind in der Tabelle mit Sternen und in Fig. 3 mit stehenden Kreuzen angegeben; sie stimmen mit den oben angeführten Verdunstungsversuchen gut überein. Es geht hieraus hervor, daß gemischte Lösungen von $\mathrm{KCl}$ und $\mathrm{KBr}$. auch von 0 bis 13,5 Mol.- $\% \mathrm{KCl}$ Mischkrystalle ausscheiden, mit ungefähr demselben Verhältnisse von $\mathrm{KCl}$ zu KBv wie in den Lösungen. Diese Tatsache ist auch technisch von Wichtigkeit. Denn wäre die von Fock angegebene Mischungslücke reell, so könnte $\mathrm{KBr}$ von einer $\mathrm{KCl}$-Verunreinigung durch Umkrystallisation getrennt werden, während in Wirklichkeit dieses Umkrystallisieren nichts, oder besser, fast nichts helfen würde.

\begin{tabular}{|c|c|c|c|c|c|c|c|c|}
\hline \multirow{2}{*}{ Nr. } & \multicolumn{2}{|c|}{$\begin{array}{c}\text { Lösung } \\
\text { Gew.-Proc. }\end{array}$} & \multicolumn{2}{|c|}{$\begin{array}{c}\text { Krystalle } \\
\text { Gew.-Proc. }\end{array}$} & \multicolumn{2}{|c|}{ Controlle } & \multirow{2}{*}{$C_{L}$} & \multirow{2}{*}{$C_{K r}$} \\
\hline & $B r$ & $C l$ & $B r$ & $\mathrm{Cl}$ & $\begin{array}{c}\text { Gew.-Proc. } \\
K \text { ber. }\end{array}$ & $\begin{array}{c}B r+C l \\
\quad+K\end{array}$ & & \\
\hline $\mathrm{KCl}$ & & & & 47,52 & & & & \\
\hline 1 & 1,92 & 14,69 & 0,99 & 47,02 & 52,41 & 100,42 & 5,47 & 0,92 \\
\hline 2 & 7,94 & 9,48 & 7,91 & 41,70 & 49,92 & 99,53 & 27,1 & 7,8 \\
\hline 3 & 13,34 & 7,43 & 17,69 & 35,08 & 47,40 & 100,17 & 44,4 & 18,3 \\
\hline 4 & 15,09 & 6,79 & 27,53 & 27,93 & 44,32 & 99,78 & 49,7 & 30,4 \\
\hline 5 & 18,70 & 5,07 & 45,37 & 14,96 & 38,73 & $\mathbf{9 9}, 06$ & 62.1 & 37,4 \\
\hline 6 & 21,00 & 3,86 & 55,40 & 8,08 & 36,05 & 99,53 & 70,7 & 75,2 \\
\hline$* 7$ & 24,39 & 1,73 & 61,02 & $\mathbf{3 , 8 8}$ & 34,16 & 99,06 & 86,1 & 87,5 \\
\hline$*_{8}$ & 25,16 & 1,21 & 63,38 & 2,41 & 33,69 & 99,48 & 90,3 & 92,1 \\
\hline 9 & 25,37 & 1,22 & 63,89 & 1,94 & 33,42 & 99,25 & 90,2 & 93,5 \\
\hline$*_{10}$ & 26,08 & 0,70 & 64,80 & 1,51 & 33,41 & 99,71 & 94,2 & 95,0 \\
\hline 11 & 25,95 & 0,68 & 64,73 & 1,39 & $\mathbf{3 3}, \mathbf{2 3}$ & 99,35 & 94,4 & 95,3 \\
\hline$K B r$ & 27,38 & & 67,13 & & & & 100 & 100 \\
\hline
\end{tabular}

1) Berl. Ber. 1903, 36, $2357-2368$.

2) Vielleicht ist es nicht überflüssig, hervorzuheben, daß, wenn einheitliche Mischkrystalle im Vergleiche zu einem Gemische aus zwei Phasen (den beiden Componenten) den stabilen Zustand bilden, dies aucb der Fall bleibt, wenn eine gesättigte Lösung mitgegenwärtig ist, vorausgesetzt, da $B$ das Lösungsmittel sich in dem Bodenkörper nicht fest lost. Ein Zerfall kann durch das Mitvorhandensein der Lösung nicht verursacht werden. 
Die übrige von mir bestimmte Gleichgewichtslinie stimmt mit der Fockschen (in Fig. 3 punktiert angegeben) teilweise gut überein und würde es noch besser tun, falls Fock die stark schlängelnde Linie von ca. 10 bis $50 \mathrm{Mol} .-\% \mathrm{KCl}$ durch eine mehr stetige Mittelcurve ersetzt hätte.

e) Carnallit-Bromcarnallit- $\mathrm{H}_{2} \mathrm{O}$. Aur S. 352 wurde schon erwähnt, daß das Doppelsalz $\mathrm{MgBr}_{2} . \mathrm{KBr} .6 \mathrm{H}_{2} \mathrm{O}$ sich krystallographisch vom Carnallit stark unterscheidet, mit lelzterem also nicht isomorph ist. Es wurde nun untersucht, ob und in wie weit Mischkrystalle von beiden möglich sind, ob somit eine Isodimorphie vorliegt. Daß $B r^{*}$ dem Carnallit isomorph beigemischt

Fig. 3.

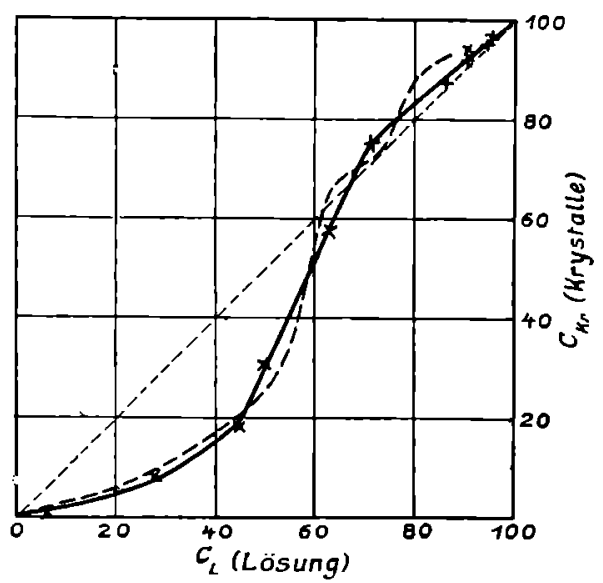

Gleichgewichtsdiagramm $\mathrm{KCl}-\mathrm{KBr}-\mathrm{H}_{2} \mathrm{O}$.

(Die Focksche Curve punktiert.) sein kann, ist bis zu einem kleinen Prozentgehalt durch die natürlichen Vorkommnisse bewiesen.

Zur experimentellen Erforschung der ganzen Mischungsreihe wurden bestimmte Mengen von $\mathrm{MgCl}_{2} \cdot 6 \mathrm{H}_{2} \mathrm{O}, \mathrm{MgBr}_{2} .6 \mathrm{H}_{2} \mathrm{O}$ und $\mathrm{KBr}$ (resp. $\mathrm{KCl}$ ) in wässeriger Lösung - so daß jedesmal ungefähr ein gewünschtes Molekularverhältnis zwischen $C l$ und $B r$ bestand - der Verdunstung bei $25^{0}$ überlassen. Das zuerst ausgeschiedene $K(C l, B r)$ wurde abfiltriert, sobald das anisotrope Doppelsalz auftrat, und das Filtrat weiter eingeengt, bis eine zur Analyse genügende Menge Krystalle vorlag. Die Krystalle wurden abgeschleudert und Mutterlauge und Krystalle analysiert. Die Berechnung der anhängenden Mutlerlauge wurde nach dem S. 350 angegebenen Verfahren ausgeführt. Für $A$ und $B$ in der Endgleichung sind einzusetzen:

$$
\begin{aligned}
& A=\frac{\left.M_{M g}{ }^{1}\right)+M_{K}+6 M_{H_{2} O}}{3 M_{O l}} \\
& B=\frac{M_{M g}+M_{K}+6 M_{H_{2} O}}{3 M_{B r}} .
\end{aligned}
$$

In der nachfolgenden Tabelle sind die Ergebnisse der Analyse und Berechnungen zusammengestellt und in Fig. 4 graphisch eingetragen.

1) Mit $M$ sind die Alom- resp. Mol.-Gewichte gemeint. 


\begin{tabular}{|c|c|c|c|c|c|c|c|c|c|c|}
\hline \multirow[t]{2}{*}{$\mathrm{Nr}$. } & \multicolumn{2}{|c|}{$\begin{array}{c}\text { Lösung } \\
\text { Gew.-Proc. }\end{array}$} & \multicolumn{2}{|c|}{$\begin{array}{l}\text { Feuchte Kr. } \\
\text { Gew.-Proc. }\end{array}$} & \multirow{2}{*}{$\begin{array}{l}\text { Proc. } \\
\text { Mutt.- } \\
\text { Lange } \\
\text { i. d. Kr. }\end{array}$} & \multicolumn{2}{|c|}{$\begin{array}{l}\text { Trockne Kr. } \\
\text { Gew.-Proc. }\end{array}$} & \multirow{2}{*}{$C_{L}$} & \multirow{2}{*}{$C_{\boldsymbol{K} r}$} & \multirow{2}{*}{ Bodenkörper } \\
\hline & $B r$ & $C l$ & $B r$ & $\mathrm{Cl}$ & & $B r$ & $C l$ & & & \\
\hline $\begin{array}{c}\text { Carn. } \\
1 \\
2 \\
3 \\
4 \\
5 \\
6 \\
7 \\
8 \\
9 \\
10 \\
B r- \\
\text { Carn. }\end{array}$ & 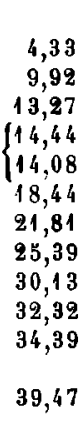 & $\begin{array}{r}19,73 \\
17,49 \\
15,26 \\
14,70 \\
14,42 \\
12,65 \\
10,83 \\
8,71 \\
6,53 \\
4,30 \\
2,63\end{array}$ & $\begin{array}{l}\mathbf{9 0 , 8 3} \\
\mathbf{2 8 , 8 4} \\
\mathbf{3 6 , 8 7} \\
44,16 \\
48,31 \\
52,62\end{array}$ & $\begin{array}{r}23,5: \\
18,49 \\
13,17 \\
\mathbf{8 , 4 8} \\
\mathbf{5 , 0 2} \\
\mathbf{2 , 2 1}\end{array}$ & $\begin{array}{r}7,8 \\
6,6 \\
7,1 \\
6,8 \\
12,3 \\
11,8\end{array}$ & $\begin{array}{r}21,03 \\
29,34 \\
37,75 \\
45,18 \\
50,56 \\
55,06 \\
58,29\end{array}$ & $\begin{array}{r}24,48 \\
19,03 \\
13,52 \\
8,61 \\
5,16 \\
2,15\end{array}$ & $\begin{array}{l}39,3 \\
47,2 \\
56,4 \\
67,8 \\
77,0 \\
85,1 \\
100\end{array}$ & $\begin{array}{r}27,6 \\
40,6 \\
55,3 \\
70,0 \\
81,3 \\
94,9 \\
100\end{array}$ & $\begin{array}{c}\text { Mischkryst. Carn. } \\
+K(\mathrm{~K}, \mathrm{Br}) \\
\text { Mischkr. Car. }+ \text { Misch } \\
\text { kr. Bromc. }+K(\mathrm{Cl}, \mathrm{Br}\end{array}$ \\
\hline
\end{tabular}

Es geht aus den Bestimmungen, verbunden mit der optischen Beobachtung der Bodenkörper hervor, daß aus Lösungen mit $c_{L}$ von 0 bis 30,2

Fig. 4.

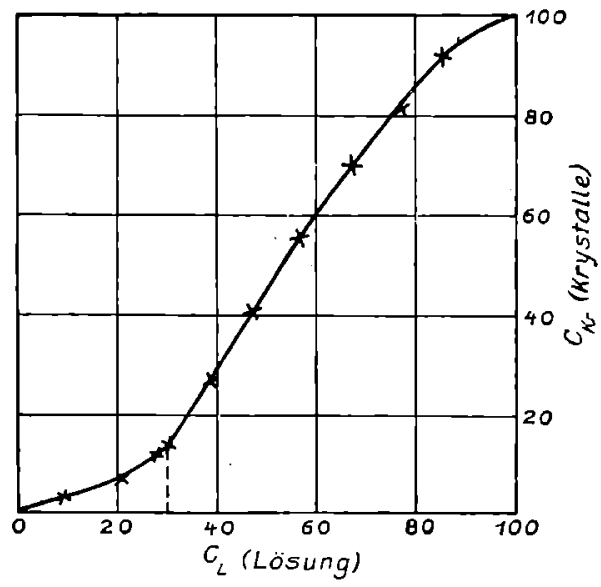

Gleichgewichtsdiagramm Carnallit-Bromcarnallit- $\mathrm{H}_{2} \mathrm{O}$. sich Mischkrystalle von dem Carnallittypus bilden, während die Lüsungen mit mehr Brom mit den prismatischen Mischkrystallen von dem Bromcarnallittypus im Gleichgewicht sind. Eine Lösung mit $14,26 \% \mathrm{Br}$ $14,56 \% C l$, also $c_{L}=30,2$, enthält die beiden Krystallarten als Bodenkörper.

Merkwürdigerweise ist die chemische Zusammensetzung dieser beiden Bodenkörper, extrapoliert aus den Daten der obigen Tabelle, nicht merklich verschieden, während der ausgeprägte krystallographische Unterschied keine Verwechslung zuläßt. Es liegt also hier der bislang, soviel mir bekannt, nicht beobachtete Fall vor, daß die Lücke in der Mischkrystallreihe von isodimorphen Körpern in bezug auf die chemische Zusammensetzung - wenn überhaupt vorhanden - innerhalb der Genauigkeitsgrenze der Bestimmungen liegt.

f) Die mit Carnallit- bezw. Bromcarnallitmischkrystallen und Lüsung im Gleichgewicht stehenden Mischkrystalle von Kaliumchlorid und -bromid. Auf S. 357 wurden schon die isotropen Kaliumhalogenidkrystalle erwähnt, welche vor der Doppelsalzausscheidung 
auftreten. Eine Bestimmung dieser Krystalle ist für die Aufstellung des vollständigen Diagramms notwendig und hat noch in zwei weiteren Hinsichten Interesse. Erstens geht aus diesen Bestimmungen hervor, wie ein hoher Magnesiumgehalt der Lüsung bei dem gleichen Verhältnis von $C l$ und $\mathrm{Br}$ die Mischkrystallbildung von Chlor- und Bromkalium beeinflußt. Zweitens kann man aus den Gleichgewichten ablesen, wie hoch der ungefähre Bromgehalt des Sylvins im Sylvinit resp. Hartsalz sein wird, weil diese sich aller Wahrscheinlichkeit nach in den meisten Fällen aus stark chlormagnesiumhaltiger Lösung abgesetzt haben.

Die Abtrennung der Kaliumhalogenidkrystalle wurde ausgeführt, indem aus größeren Mengen der gemischten Lösungen (ca. $700 \mathrm{~g}$ ) die sich bei der Einengung allmählich abscheidenden isotropen Krystalle drei- bis viermal nach einander fortgenommen und von anhängender Mutterlauge gereinigt wurden. Als schließlich die Doppelsalzkrystalle ${ }^{1}$ ) auftraten, wurde die zuletzt abgetrennte Menge Kaliumhalogenid zur Analyse benutzt.

\begin{tabular}{|c|c|c|c|c|c|}
\hline \multirow[b]{2}{*}{$C_{L}$} & \multicolumn{2}{|c|}{ Kryst. Gew.-Proc. } & \multicolumn{2}{|c|}{ Controlle } & \multirow[b]{2}{*}{$C_{\boldsymbol{K} \boldsymbol{r}}$} \\
\hline & $B r$ & $C l$ & $\begin{array}{c}\text { Gew. Proc. } \\
K \text { ber. }\end{array}$ & $\begin{array}{c}B r+C l \\
+K\end{array}$ & \\
\hline 8,53 & 2,91 & 15,37 & $51, ; 33$ & 99,81 & 2,76 \\
\hline 20,1 & 7,85 & 41,36 & 49,72 & 99,13 & 7,73 \\
\hline 27,8 & 12,40 & 38,43 & 48,51 & 99,34 & 12,5 \\
\hline 39,3 & 26,20 & 28,88 & 44, & 99,74 & 98,7 \\
\hline 47,2 & 44,23 & 16,02 & 39 & 99,60 & 55,0 \\
\hline 56.4 & 54 & 8.91 & 36, & 99,56 & 72.9 \\
\hline 67.8 & & 21 & 34, & 99,46 & 83.5 \\
\hline 77,0 & & & & 99,83 & 89,8 \\
\hline 85,1 & 64,04 & 1,84 & 33,39 & 99,27 & 93,9 \\
\hline
\end{tabular}

Man sieht aus der Fig. 5, wo die Linie der Fig. 3 punktiert mit angegeben ist, daß die Gegenwart von Magnesiumhalogenid die Aufnahmefähigkeit des Chlorkaliums für Brom bedeutend erhöht, im Gegensatze zu der üblichen Annahme, daß das Brom in Salzgemischen immer an Magnesium gebunden sei.

g) Vollständiges Gleichgewichtsdiagramm des Systems $K$, $\mathrm{Mg}, \mathrm{Cl}, \mathrm{Br}, \mathrm{H}_{2} \mathrm{O}$ bei $25^{\circ}$. In dem vollständigen Diagramm werden vier Flächen auftreten, welche die Concentrationen angeben für die Lösungen, die resp. mit $K(\mathrm{Cl}, \mathrm{Br})$, mit Carnallitmischkrystallen, mit Bromcarnallitmischkrystallen und mit $\mathrm{Mg}(\mathrm{Cl}, \mathrm{Br})_{2} .6 \mathrm{H}_{2} \mathrm{O}$ im Gleichgewicht sind. In Fig. 6 sind diese Flächen gezeichnet. Sie schneiden sich in Linien, welche die Sättigung an zwei Bodenkörpern darstellen, und stoßen zweimal in einem Punkte zusammen bei gleichzeitiger Sättigung an drei Bodenkörpern. Die uberein.

1) Diese wurden wiederum analysiert und stimmlen mit der Tabelle S. 358 gut 
Festlegung des Punktes $J$ wurde schon auf S. 358 beschrieben. Der Punkt $K$ wurde gefunden, indem erst zwei im Verhältnisse von $\mathrm{Cl}$ zu $\mathrm{Br}$ wenig

Fig. 5.

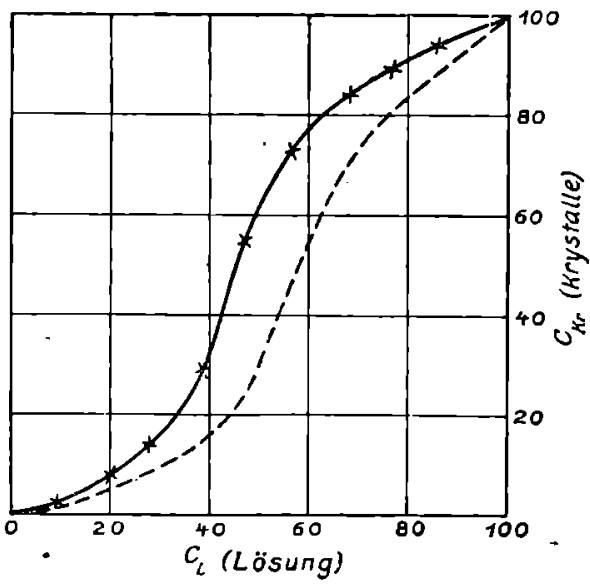

Gleichgewichtsdiagramm für $K(\mathrm{Cl}, \mathrm{Br})$ aus an Carnallit- bezw. Bromcarnalltmischkrystallen gesłttigter Lösung (punktiert dasselbe ohne Gegenwart von $\boldsymbol{M g}$ ).
Fig. 6.

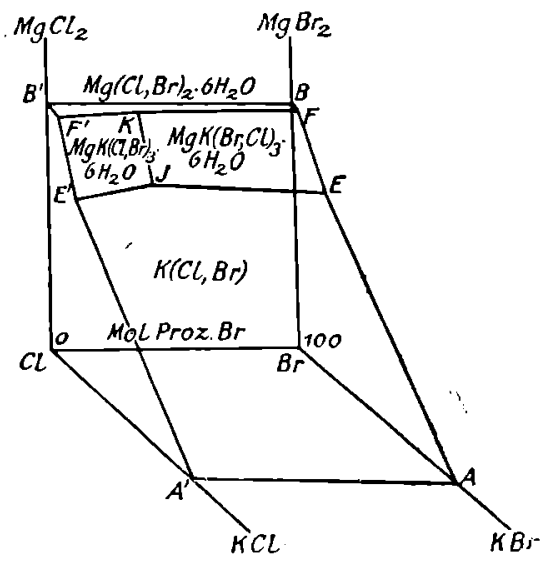

Gleichgewichtsdiagramm $\mathrm{K}, \mathrm{Mg}, \mathrm{Cl}, \mathrm{Br}, \mathrm{H}_{2} \mathrm{O}$ bei $25^{0}$.

verschiedene Lösungen gesucht wurden, die neben $\mathrm{Mg}(\mathrm{Cl}, \mathrm{Br})_{2} \cdot 6 \mathrm{H}_{2} \mathrm{O}$ nur Doppelsalzkrystalle von dem Carnallit- resp. Bromcarnallittypus zeigten. $Z$ wischen diesen Grenzen wurden Lösungen gefunden, welche beide Doppelsalzmischkrystallarten neben einander als Bodenkörper enthielten. Die Analyse der Lösungen, welche von den Punkten $J$ und $K$ dargestellt werden, ergab:

\begin{tabular}{lcc||cc}
\hline & \multicolumn{2}{c||}{$J$} & \multicolumn{2}{c}{$K$} \\
\hline & I & II & I & II \\
\hline$B r$ & $14,44 \%$ & $14,08 \%$ & $17,10 \%$ & $16,65 \%$ \\
$C l$ & 14,70 & 14,42 & 16,93 & 16,49 \\
$M g$ & 6,78 & 6,75 & 8,36 & 8,36 \\
$K$ & 1,45 & 1,43 & 0,03 & 0,05
\end{tabular}

Das Mittel ergibt bei Berechnung als Moleküle auf 1000 Mol. Wasser

$\begin{array}{llllllll}\text { Punkt } J \quad 1000 \mathrm{H}_{2} \mathrm{O} & 51,0 \mathrm{Br} & 117,6 \mathrm{Cl} & \mathbf{7 9 , 5} \mathrm{Mg} & 10,5 \mathrm{~K}\end{array}$ $\begin{array}{lllll}\text { Punkt } \mathrm{K} 1000 \mathrm{H}_{2} \mathrm{O} & 65,6 \mathrm{Br} & 146,4 \mathrm{Cl} & 106,8 \mathrm{Mg} & 0,3 \mathrm{~K}\end{array}$

Das Molekularverhältnis von $B r$ zu $B r+C l$ ist für $J 30,2$; für $K 30,9$.

III. Das System $\mathrm{NaCl}-\mathrm{NaBr}-\mathrm{H}_{2} \mathrm{O}$.

Weil als Begleiter der Kalium- und Magnesiumsalze in den Lagerstätten auch immer Steinsalz auftritt, wurde das Verhalten der gemischten Lösungen 
Uber d. Krystallisationsschema d. Chloride, Bromide, Jodide v. Natrium usw. 361

von $\mathrm{NaCl}$ und $\mathrm{NaBr}$ bei $25^{\circ}$ untersucht. Über die Componenten ist bekannt, daß Bromnatrium bis zu einer Temperatur von 50,701) aufwärts aus wässeriger Lösung als Dihydrat auskrystallisiert, oberhalb dieser Temperatur wasserfrei. Beim Chlornatrium ist das Dihydrat nach Meyerhoffer und Saunders ${ }^{2}$ ) schon über $0,15^{\circ}$ nicht mehr existenzfähig. Weiterhin sind die wasserfreien gemischten Schmelzen von $\mathrm{NaCl}$ und $\mathrm{NaBr}$ von Ruff und Plat ${ }^{3}$ ) untersucht worden; ihre Bestimmungen lassen auf eine lückenlose Reihe von Mischkrystallen zwischen den beiden Salzen schließen.

Die Erzeugung und das Trocknen der Krystalle, ebenso die Analyse derselben und der gesättigten Jösung geschah in der für $K C l-K B r$ angegebenen Weise. Aus den bromreichen Lösungen krystallisierte ein monoklines Hydrat aus; dieses wurde mittels Centrifugieren abgetrennt und die anhängende Mutterlauge nach der Methode von S. 350 in Rechnung gebracht. Dabei ist die Formel $\mathrm{Na}(C l, B r) .2 \mathrm{I}_{2} \mathrm{O}$ für die Mischkrystalle angenommen. Diese Annahme erscheint berechtigt, weil sich aus den Analysenzahlen der Krystalle, ohne Correctur für die anhaftende Mutterlauge, ein Molekularverhältnis $\mathrm{II}_{2} \mathrm{O}: \mathrm{Na}=2,06$ ergibt.

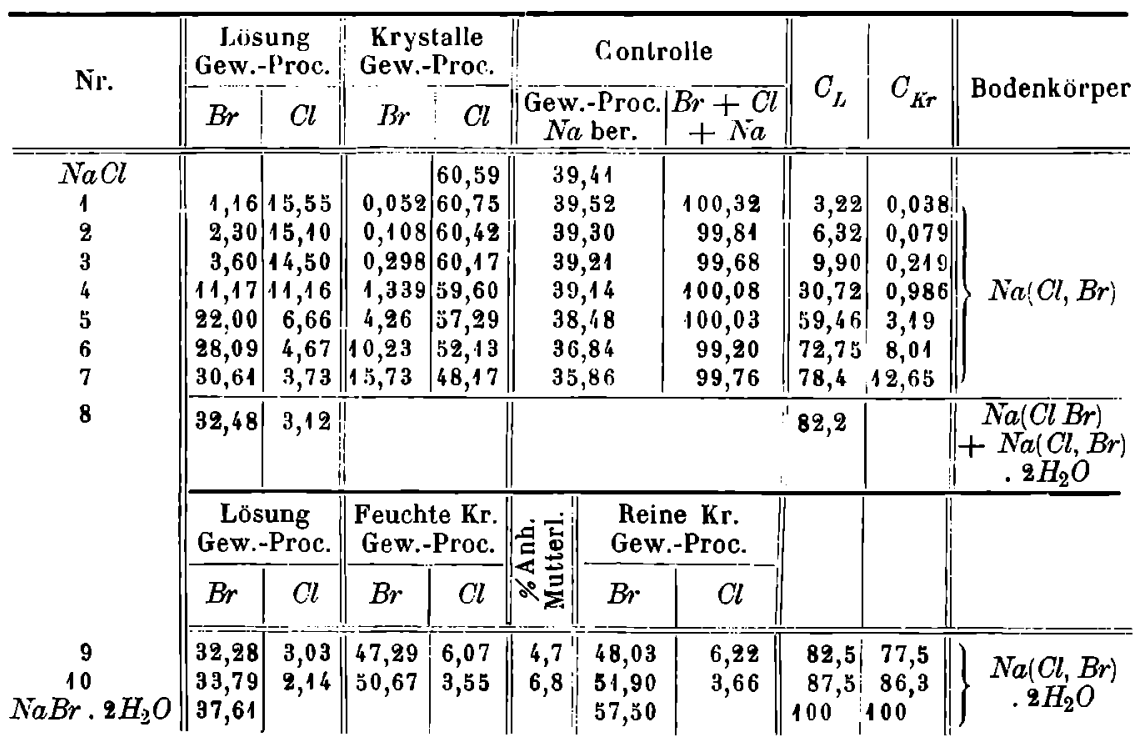

Es geht aus den Bestimmungen hervor, daß die Aufnahmefähigkeit von Chlornatrium für Brom in fester Lösung außerordentlich gering ist. Erst bei ca. $65 \mathrm{Mol} \% \mathrm{Br}$ biegt sich die Gleichgewichtslinie deutlich um;

1) Genau 50,6740, Richards und Churchill, Zeitschr. f. phys. Chem. 1906 , 56, 348-361.

2) Zeitschr. f. phys. Chem. 1899, 28, 461. Ausz. diese Zeilschr. 35, 376.

3) Berl. Ber. 1903, 36, 2357-2368. 
sie wird dann aber abgeschnitten durch die Bildung von Dihydrat. Umgekehrt wird die Entwässerungstemperatur von $\mathrm{NaBr} .2 \mathrm{H}_{2} \mathrm{O}$ durch Aufnahme von Chlor in fester Lösung heruntergedrückt und liegt (nach der Extrapolierung aus den Zahlen der Tabelle) für $C_{K r}=77,2$ schon bei $25^{\circ}$.

Fig. 7.

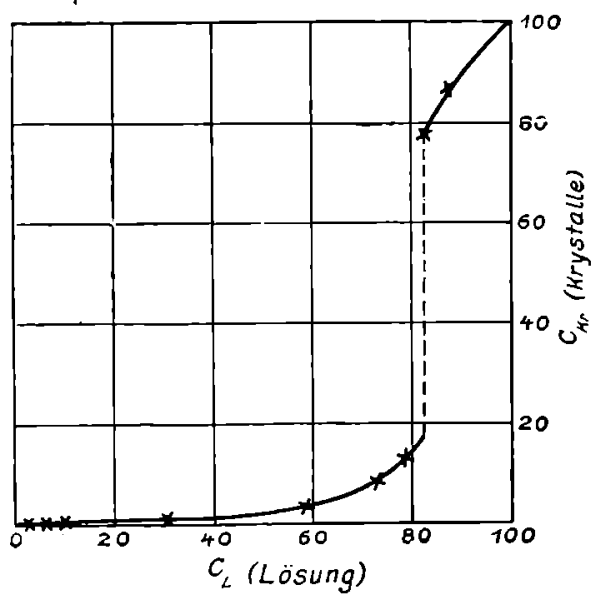

Gleichge wichtsdiagramm $\mathrm{NaCl}-\mathrm{NaBr}-\mathrm{H}_{2} \mathrm{O}$ bei $25^{\circ}$
Fig. 8.

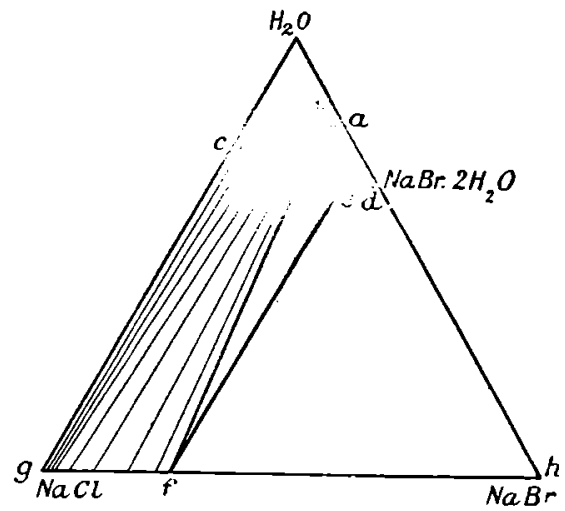

Gleichgewichtsschema $\mathrm{NaCl}-\mathrm{NaBr}-\mathrm{H}_{2} \mathrm{O}$ bei 250 .

Der Zerfall findet dann statt zu einer Lösung mit $C_{L}=82,2$ und Mischkrystallen $\mathrm{Na}(\mathrm{Cl}, \mathrm{Br})$ mit 17,5 Mol.-\% $\% \mathrm{NaBr}$. Die Löslichkeit des $\mathrm{NaBr} .2 \mathrm{H}_{2} \mathrm{O}$ bei 250 wurde durch Schütteln im Thermostaten ermittelt und ergab: I. "37,60\% $\mathrm{Br}=48,43 \% \mathrm{NaBr}$; II. $37,61 \% \mathrm{Br}=48,45 \% \mathrm{NaBr}$. Etard fand $47,86 \% \mathrm{NaBr}$ nach der von ihm angegebenen Formel ${ }^{1}$ ).

Es ist aus der Fig. 7 nicht ersichtlich, daß die bromreichen Mischkrystalle mit zwei Molekülen Wasser krystallisieren; deshalb ist eine Darstellung der Verhältnisse unter gleichmäßiger Berücksichtigung der drei Componenten in Fig. 8 angegeben. Die Linie $d e$ enthält die Dihydratmischkrystalle, welche mit den Lösungen auf $a b$ im Gleichgewicht sind, ebenso sind die wasserfreien Mischkrystalle auf der Strecke $g f$ neben den Lösungen auf $c b$ existenzfähig. Das Dreieck $b c f$ gibt die Coexistenz dreier Phasen an (Lösung + Dihydrat + anhydrische Mischkrystalle). Aus den Daten läßt sich folgern, daß bei höherer Temperatur das Viereck $e b f g$ an Ausdehnung zunimmt, das Viereck abed dagegen sich verkleinert; bei $50,7^{\circ}$ verschwindet das letztere (weil die Zerfalltemperatur von $\mathrm{NaBr} .2 \mathrm{H}_{2} \mathrm{O}$ bei Aufnahme von $\mathrm{Cl}$ in fester Lösung nicht durch ein Maximum geht ${ }^{2}$ ), und

1) Compt. rend, $1884,96,1432$.

2) Vgl. Richards und Churchill, Zeitschr. f. phys. Chem. 1906, 56, 348-361, 
Über d. Krystallisationsschema d. Chloride, Bromide, Jodide v. Natrium usw. 363

Punkt $f$ ist mit $h$ zusammengefallen. Umgekehrt kommt durch Temperaturerniedrigung das Viereck $c b f g$ bei $0,15^{\circ}$ zum Verschwinden.

Daß auch die wasserfreien Mischkrystalle mit höherem Bromgehalt bei gewöhnlicher Temperatur instabil existenzfähig sind, geht aus der Beobachtung hervor, daß eine Schmelze von gleichen molekularen Mengen $\mathrm{NaCl}$ und $\mathrm{NaBr}$ zu einer homogenen, klaren Mischkrystallmasse erstarrte, die bei der Abkühlung auf Zimmertemperatur keine Änderung erfuhr; allmählich aber wurden die Krystalle beim Liegen an der Luft trübe und zeigten sie sich dann zerfließlich.

IV. Krystallisation der Lösungen von $K, M g, C l$ mit kleinem Bromgehalt, unter gleichzeitiger Sättigung an Chlornatrium.

Die natürlichen Salzablagerungen führen regelmäßig Steinsalz als Begleiter der Kalium- und Magnesiumsalze. Deshalb wurde für kleinere Gehalte an Brom in der Lösung der Einfluß einer gleichzeitigen Sättigung an Chlornatrium auf den Bromgehalt der Chlorkalium- und der Carnallitmischkrystalle studiert.

a) Chlorkalium und Chlornatrium. Wie früher wurden die bei $25{ }^{0}$ gesättigte Lösung und die ausgeschiedenen Krystalle analysiert. Nach der indirecten Chloridmethode wurden $K$ und $\mathrm{Na}$ im Krystallgemisch bestimmt. Man kann aber selbstverständlich aus der vollständigen Analyse des Gemisches nicht entscheiden, wieviel Brom an. $K$, wieviel an $N a$ gebunden ist. Deshalb wurde aus den Tabellen auf $S .356$ und 361 für $\mathrm{KCl}-\mathrm{KBr}-\mathrm{H}_{2} \mathrm{O}$ und $\mathrm{NaCl}-\mathrm{NaBr}-\mathrm{H}_{2} \mathrm{O}$ berechnet, wie groß der Bromgehalt des kalium- und natriumhaltigen Gemisches sein müßte, wenn nur $C_{L}$, nicht die Mitanwesenheit von $\mathrm{Na}$ resp. $K$ in der Lösung auf die Mischkrystallbildung von Einfluß wäre. Aus den untenstehenden Zahlen geht hervor, daß die Berechnung mit dem Gefundenen übereinstimmt. Weiter zeigte sich bei der Lüsung mit einem $C_{L}=19,76$, daß die zuerst ausgefallenen und analysierten Krystalle kaliumfrei waren. Hier konnte also das Natriumsalz bei fast erreichter Sättigung an Kaliumsalz für sich analysiert werden, und ergab sich wiederum kein merklicher Einfluß der Gegenwart des Kaliums in der Lösung.

\begin{tabular}{|c|c|c|c|c|c|c|c|}
\hline \multirow{2}{*}{$C_{L}$} & \multicolumn{4}{|c|}{ Kryslalle, Gewichts-Procente } & \multicolumn{3}{|c|}{ Berechn. Bromgebalt in Gew.-Proc } \\
\hline & $B r$ & $\mathrm{Cl}$ & $K$ & $N a$ & für $K$-Salz & Pür $\mathrm{Na}$-Salz & Total \\
\hline $\begin{array}{c}9,46 \\
13,0 \\
19,76\end{array}$ & $\begin{array}{l}1,242 \\
1,421 \\
0,871\end{array}$ & $\begin{array}{l}52,53 \\
55,67 \\
60,42\end{array}$ & $\begin{array}{c}28,64 \\
15,36 \\
-\end{array}$ & $\begin{array}{c}17,62 \\
27,55 \\
-\end{array}$ & $\begin{array}{c}1,286 \\
1,04 \\
-\end{array}$ & $\begin{array}{l}\mathbf{0 , 1 2 3} \\
0,318 \\
0,79\end{array}$ & $\begin{array}{l}1,409 \\
1,36 \\
0,79\end{array}$ \\
\hline
\end{tabular}

b) Carnallit und Chlornatrium. Weil Chlornatrium in der an 
Carnallit gesättigten Lösung nur sehr wenig löslich ist, war ein Einfluß des Chlornatriums auf den Bromgehalt des Carnallits nicht zu erwarten. Zur zahlenmäßigen Prüfung wurden aus zwei Lösungen die etwas chlornatriumhaltigen Carnallitmischkrystalle analysiert in bezug auf $\mathrm{Br}, \mathrm{Cl}$ und $\mathrm{Mg}{ }^{1}$ ). Nach Anbringen der Correctur für die anhaftende Mutterlauge wurde das Verbältnis von Brom und Magnesium mit dem nach der Tabelle für Carnallit-Bromcarnallit-Wasser (S. 358) berechneten verglichen. Es ergab sich das folgende:

\begin{tabular}{|c|c|c|c|c|c|c|}
\hline \multirow{2}{*}{$C_{L}$} & \multicolumn{3}{|c|}{$\begin{array}{l}\text { Gew.-Proc. i. d. Kryst. corrig. } \\
\text { auf Laugenfreibeit }\end{array}$} & \multicolumn{3}{|c|}{$\begin{array}{l}\text { berechnet f. Carnallit-Brom- } \\
\text { Carnallit- } \mathrm{H}_{2} \mathrm{O}\end{array}$} \\
\hline & $B r$ & $M g$ & $\frac{B r}{M g}$ & $B r$ & $M g$ & $\begin{array}{l}B r \\
M g\end{array}$ \\
\hline $\begin{array}{r}8,45 \\
18,98\end{array}$ & $\begin{array}{l}\mathbf{2}, 00 \\
\mathbf{5 , 3 3}\end{array}$ & $\begin{array}{l}8,42 \\
7,87\end{array}$ & $\begin{array}{l}0,238 \\
0,678\end{array}$ & $\begin{array}{l}2,16 \\
5,48\end{array}$ & $\begin{array}{l}8,66 \\
8,58\end{array}$ & $\begin{array}{l}\mathbf{0 , 2 5 0} \\
\mathbf{0 , 6 4 0}\end{array}$ \\
\hline
\end{tabular}

Einen Einfluß in einer bestimmten Richtung übt also die Gegenwart von Chlornatrium auf den Bromgehalt der Carnallitkrystalle nicht aus.

Von größerem Interesse ist es, den umgekehrten Einfluß, nämlich denjenigen von einem großen Magnesiumgehalt in der Lösung auf den Bromgehalt des Chlornatriums zu bestimmen. Dazu wurden die aus einer größeren Menge von fast an Chlormagnesium gesättigter Lösung zuerst ausfallenden Chlornatriumkrystalle analysiert.

\begin{tabular}{|c|c|c|c|c|c|c|}
\hline \multirow[b]{2}{*}{$C_{L}$} & \multicolumn{2}{|c|}{ Kryst.-Gew.-Proc. } & \multicolumn{2}{|c|}{ Controlle } & \multicolumn{2}{|c|}{$C_{K r}$} \\
\hline & $B r$ & $\mathrm{Cl}$ & $\begin{array}{l}\text { Gew.-Proc. } \\
N a \text { ber. }\end{array}$ & $B r+C l+N a$ & gef. & $\begin{array}{l}\text { ber. f. } \mathrm{NaCl}- \\
\mathrm{NaBr}-\mathrm{H}_{2} \mathrm{O}\end{array}$ \\
\hline $\begin{array}{r}5,91 \\
12,26\end{array}$ & $\begin{array}{l}0,178 \\
0,567\end{array}$ & $\begin{array}{l}60,23 \\
59,88\end{array}$ & $\begin{array}{l}39,20 \\
39,09\end{array}$ & $\begin{array}{l}99,61 \\
99,54\end{array}$ & $\begin{array}{l}0,13 \\
0,42\end{array}$ & $\begin{array}{l}0,074 \\
0,31\end{array}$ \\
\hline
\end{tabular}

Magnesiumhaltige Mutterlauge war in diesen Krystallen nicht merklich eingeschlossen.

Ebenso wie es beim Chlorkalium gefunden wurde (S. 359), vergrößert das Vorhandensein eines großen Magnesiumgehaltes in der Lösung die Aufnahmefähigkeit des Chlornatriums für Brom; die letztere bleibt allerdings auch in diesem Falle noch sehr gering.

\section{Tachhydrit und Kainit.}

Von den in größeren Mengen vorkommenden Chlorverbindungen der Kaliumsalzlagerstätten sind noch Tachhydrit und Kainit zu nennen.

1) Eine Trennung der beiden Krystallarten nach dem specifischen Gewichte ließ sich nicht ausführen, weil die Krystallmasse sich zusammenballt (wobl infolge der anhängenden Multerlauge) und gleichzeitig in der schweren Fliissigkeit steigt, resp. sinkt. 
Tachhydrit. Dieses Mineral $2 \mathrm{MgCl}_{2} \cdot \mathrm{Ca} \mathrm{Cl}_{2} \cdot 12 \mathrm{H}_{2} \mathrm{O}$ wurde dargestellt nach van't $\left.H_{\circ f}{ }^{1}\right)$, und daneben eine entsprechende Lösung, in welcher ca. $\mathbf{5} \%$ des Chlors durch äquivalentes Brom ersetzt war, der Krystallisation bei 250 überlassen. Die dem Tachhydrit ähnlichen Krystalle wurden zerkleinert und centrifugiert.

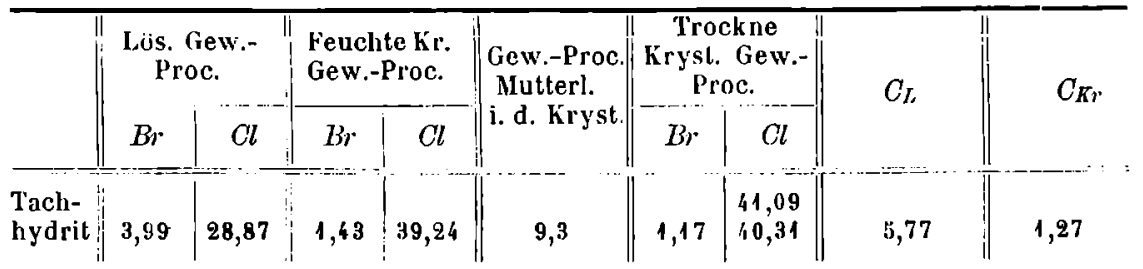

Daraus geht hervor, daß der Tachhydrit Brom in isomorpher Vertretung des Chlors aufnehmen kann, aber bei demselben $C_{L}$ weniger als es beim Carnallit der Fall ist. Die Analysen von natürlichem Tachhydrit (S. 388) bestätigen diesen Befund.

De Schulten ${ }^{2}$ ) hat vergeblich versucht, einen Bromtachhydrit darzustellen. Vielleicht würde sich bei systematischen Bemühungen dennoch ein Existenzgebiet für diese Verbindung ergeben, wie es sich für den verwandten Bromcarnallit gefunden hat.

Kainit. Bei meinen Versuchen, Kainit $\left(\mathrm{MgSO}_{4} \cdot \mathrm{KCl} .3 \mathrm{H}_{2} \mathrm{O}\right)$ aus bromhaltiger Lösung auskrystallisieren zu lassen unter Benutzung der von van' $t H$ of $f^{3}$ ) für die Kainitdarstellung angegebenen Zahlen sind außer Chlornatrium auch immer noch andere Salze (vor allem Carnallit) mit ausgefallen. Weil der natürliche Kainit nur äußerst wenig Brom enthält (vergl. S. 388), wurde auf die Bildungsverhältnisse dieses gemischten Doppelsalzes nicht näher eingegangen. Von de Schulten ${ }^{2}$ ) wurden vergebliche Versuche zur Darstellung eines Bromkainits $\left(\mathrm{MgSO}_{4} \cdot \mathrm{KBr} \cdot 3 \mathrm{H}_{2} \mathrm{O}\right)$ ausgeführt.

\section{Einflue der Temperatur auf die Gleichgewichte bei kleinem Bromgehalt der Lösung.}

Es liegen einige Beobachtungen vor, welche darauf hindeuten, daB die Bildung der Salzablagerungen bei einer hüheren Temperatur als 250 vor sich gegangen ist (vergl. S. 375 fr.). Deshalb war die Bestimmung des Temperatureinflusses auf die Bromaufnahme der in Betracht kommenden Salze von Wichtigkeit. Zur Beantwortung dieser Frage wurden für kleineren Bromgehalt in der Lüsung auch bei $45^{\circ} \mathrm{Krystallisationen} \mathrm{von} \mathrm{Chlornatrium,}$ Chlorkalium und Carnallit ausgeführt.

1) Zeitschr. f. anorg. Chem. 1903, 47, 271. Ausz. diese Zeitschr. 44, 317.

2) Bull. Soc. Chem. 1897, 17, 165-167. Ausz. diese Zeitschr. 31, 179.

3) Oz. Salzabl. 1905, 1, 70. 
Die Bestimmungen sind in den untenstehenden Tabellen vereinigt, und in der letzten Spalte ist angegeben, welche Mischkrystalle bei $25^{\circ}$ durch dasselbe Verhältnis von Brom und Chlor in der Lösung bedingt werden. Die letzteren Zahlen sind durch Interpolierung aus den Krystallisationsergebnissen bei $25^{\circ}$ abgeleitet.

Chlornatrium.

\begin{tabular}{|c|c|c|c|c|c|c|c|c|}
\hline \multicolumn{4}{|c|}{ Lüs. Gew.-Proc. } & \multicolumn{2}{|c|}{ Controlle } & \multirow[b]{2}{*}{$C_{L}$} & \multirow[b]{2}{*}{$C_{K r} \cdot \mathrm{b} \cdot 45^{0}$} & \multirow[b]{2}{*}{$C_{K v} \cdot \mathbf{b}, 250$} \\
\hline $\mathrm{Br}$ & $\mathrm{Cl}$ & $B r$ & $C l$ & $\begin{array}{l}\text { Gew.-Proc. } \\
\mathrm{Na} \text { ber. }\end{array}$ & $\begin{array}{c}\mathrm{Br}+\mathrm{Cl} \\
+\mathrm{Na}\end{array}$ & & & \\
\hline 5,10 & 13,91 & 0,486 & $60, \mathbf{3 0}$ & 39,34 & 100,13 & 14,0 & 0,36 & 0,37 \\
\hline 9,44 & 11,99 & 1,203 & 59,67 & 39,14 & 100,01 & 25,9 & 0,89 & 0,81 \\
\hline
\end{tabular}

Chlorkalium.

\begin{tabular}{|c|c|c|c|c|c|c|c|c|}
\hline \multicolumn{2}{|c|}{ Lüs. Gew.-I'roc. } & \multicolumn{2}{|c|}{ Kryst. Gew.-Proc. } & \multicolumn{2}{|c|}{ Controlle } & & \multirow[b]{2}{*}{$C_{K r} \cdot \mathrm{b} .450$} & \multirow[b]{2}{*}{$O_{K} \cdot \mathbf{b} . \mathbf{2 5 0}$} \\
\hline$B r$ & $C l$ & $B r$ & $C l$ & $\begin{array}{c}\text { Gew.-Proc. } \\
K \text { ber. }\end{array}$ & $\begin{array}{c}B r+C l \\
+K\end{array}$ & $C_{L}$ & & \\
\hline 3,39 & 12,92 & 2,331 & 46,12 & 52,07 & 100,42 & 10,4 & 2,19 & 2,49 \\
\hline 6,77 & 11,32 & 5,66 & 43,35 & 50,64 & 99,65 & 21,0 & 5,48 & 5,0 \\
\hline
\end{tabular}

Carnallit.

\begin{tabular}{|c|c|c|c|c|c|c|c|c|c|}
\hline \multicolumn{2}{|c|}{$\begin{array}{l}\text { Lös. Gew.- } \\
\text { Proc. }\end{array}$} & \multicolumn{2}{|c|}{$\begin{array}{l}\text { Feuchte Kr. } \\
\text { Gew.-Proc. }\end{array}$} & \multirow{2}{*}{$\begin{array}{c}\text { Proc. Mutter- } \\
\text { lauge i. d. } \\
\text { Krystallen }\end{array}$} & \multicolumn{2}{|c|}{$\begin{array}{l}\text { Trockne Kr. } \\
\text { Gew.-Proc. }\end{array}$} & \multirow{2}{*}{$C_{L}$} & \multirow{2}{*}{$C_{K r}$, b. 400} & \multirow{2}{*}{$C_{K r}$, b. 250} \\
\hline$B r$ & $\mathrm{Cl}$ & $B r$ & $C l$ & & $B r$ & $C l$ & & & \\
\hline $\begin{array}{l}2,419 \\
4,65 \\
9,75\end{array}$ & $\begin{array}{l}21,96 \\
20,88 \\
18,16\end{array}$ & $\begin{array}{l}1,503 \\
2,901 \\
7,11\end{array}$ & $\begin{array}{l}35,93 \\
35,02 \\
32,43\end{array}$ & $\begin{array}{l}9,2 \\
9,5 \\
8,6\end{array}$ & $\begin{array}{l}1,41 \\
2,72 \\
6,86\end{array}$ & $\begin{array}{l}37,34 \\
36,51 \\
33,65\end{array}$ & $\begin{array}{r}4,66 \\
8,98 \\
19,84\end{array}$ & $\begin{array}{l}1,65 \\
3,20 \\
8,30\end{array}$ & $\begin{array}{l}1,40 \\
2,73 \\
6,62\end{array}$ \\
\hline
\end{tabular}

Aus diesen Zahlen geht hervor, daß beim Natrium- und Kaliumchlorid kein merklicher 'Temperatureinfluß vorhanden ist; in bezug auf Carnallit ist bei zunehmendem Bromgehalt allerdings eine etwas gesteigerte Aufnahmefähigkeit für Brom in den Krystallen bei der hüheren Temperatur zu beobachten.

B. Anwendungen auf das natürliche Vorkommen.

I. SchluBfolgerungen aus dem synthetischen Teile.

Aus den mitgeteilten Krystallisationsversuchen läßt sich folgern, daß die bisherige Auffassung, daß nur die magnesiumhaltigen Chlorsalze der Lagerstätten (Carnallit, Bischofit, Tachhydrit) bromhaltig sind, und daß bei der Verarbeitung des Carnallits auf Chlorkalium alles Brom in die Endlauge hineingeht, nicht richtig ist. Vielmehr hat sich gezeigt, daß auch das 
Über d. Krystallisationsschema d. Chloride, Bromide, Jodide v. Natrium usw. 367

Chlorkalium einen recht merklichen Bromgehalt beim Krystallisieren aus einer bromidhaltigen Lösung erhält, und daß diese Fähigkeit zur Mischkrystallbildung durch die Gegenwart von viel Chlormagnesium in der Lösung steigt anstatt $z u$ fallen.

Die schon längst bekannte sehr geringe Bromführung des Steinsalzes findet ihre Eirklärung in den auf S. 361 mitgeteilten Ergebnissen. Auch wenn die Mutterlauge schon relativ reich an Bromid ist, scheidet das Steinsalz sich fast rein aus, und dieses Verhalten wird durch Mitvorhandensein von Kaliumchlorid in der Lösung nicht merklich, durch Chlormagnesium etwas beeinflußt. Andererseits ist der zu erwartende Bromgehalt des Steinsalzes gar nicht etwa unmerklich klein, nämlich immerhin ca. ${ }_{1}^{1}$ - desjenigen vom Carnallit beim Krystallisieren aus derselben etwas bromhaltigen Lösung.

Eine Übersicht über den Bromgehalt der verschiedenen in Betracht kommenden Salze für eine Temperatur von $25^{\circ}$ bis $45^{\circ}$ bei einem Bromgehalt von einem Molekülprocent Brom bezogen auf Chlor plus Brom in der Lösung, gibt die nachfolgende 'Tabelle.

\begin{tabular}{|c|c|c|}
\hline & $100 \frac{\text { Mol. } B r}{\text { Mol. } B r+\text { Mol. } C l}$ & $\begin{array}{c}\text { Gew.-Proc. } B \text { r in del } \\
\text { Krystallen }\end{array}$ \\
\hline I.̈̈sung & 1 & \\
\hline Bischofit & 0,5 & 0,39 \\
\hline Carnallit & 0,32 & 0,28 \\
\hline $\begin{array}{l}\text { Sylvin, aus an Carnallit } \\
\text { gesättigter Lösung }\end{array}$ & 0,34 & 0,36 \\
\hline $\begin{array}{l}\text { Sylvin aus } M g \text {-freier Lü- } \\
\text { sung }\end{array}$ & 0,18 & 0,19 \\
\hline $\begin{array}{l}\text { Tachhydrit } \\
\text { steinsalz, aus stark } M y \text { - }\end{array}$ & $0,2-2$ & 0,20 \\
\hline $\begin{array}{l}\text { haltiger Lousung } \\
\text { Steinsalz, aus } M f g \text {-freier }\end{array}$ & 0,018 & 0,025 \\
\hline Lösung & 0,012 & 0,016 \\
\hline
\end{tabular}

Bei den natürlichen Salzvorkommen ist zu berücksichtigen, daß auch Sulfate in der Lösung vorhanden waren; inwieweit dadurch eine Verschiebung in den Zahlen bewirkt wird, wurde noch nicht untersucht.

Zur Prüfung der oben mitgeteilten Verhältnisse bei den natürlichen Vorkommen mußte erst eine einwandsfreie Bestimmungsmethode ausgearbeitet werden.

\section{Analytische Methode der Bestimmung von Bromid neben stark überwiegendem Chlorid, sowie über die Bestimmung von Carnallit.}

Von den älteren Methoden sei nur mitgeteilt, daß eine Nachprüfung mit Zusälzen einer bekannten Bromidmenge zu den sorgfältig entbromten Salzgemischen schwankende und im allgemeinen zu niedrige Zahlen ergab. 
Eine genaue und zuverlässige Methode wurde gefunden in einer zweimaligen Destillation nach dem Friedheim-Meyerschen Princip (vgl. S. 350). Die Salzprobe (bei Carnallit $10 \mathrm{~g}$, bei weniger bromhaltigen Proben entsprechend mehr) wird mit $10 \mathrm{~g}$ Kaliumbichromat in Wasser gelöst und durch den eingeschliffenen Hahntrichter des Destillierkolbens ${ }^{1)} 20 \mathrm{ccm}$ von mit dem gleichen Volumen Wasser verdünnter Schwefelsäure eingelührt; darauf wird mit Wasser auf ca. $200 \mathrm{ccm}$ angefüllt. In der Vorlage, welche fast ganz in ein Gefäß mit Küblwasser eintaucht, befindet sich eine Lösung von $1 \mathrm{~g}$ Kaliumhydroxyd in Wasser, und auch das Perlrohr auf der Vorlage ist mit Kalilauge beschickt. Vorlage und Ableitungsrohr des Kolbens sind mittels eines Kautschukpfropfens verbunden, welcher während der Destillation ein- oder zweimal gelüftet wird. Der Inhalt des Kolbens wird ca. 20 Minuten gekocht und dabei auf $150 \mathrm{ccm}$ eingeengt, dann wird noch 20 Minuten lang ein Kohlensäurestrom eingeleitet bei Verkleinerung der untergestellten Flamme. Hierbei geht alles Brom in die Vorlage über und etwas, aber sehr wenig Chlor 2); auch verflüchtigt sich etwas Salzsäure. Während der Destillation wird das Kühlwasser der Vorlage nicht im Strömen gehalten, damit der Inhalt der Vorlage sich erwärmt, und das miltgebildete Kaliumhypobromit in Bromat übergeht.

Nach beendeter Destillation wird der Kolben von der Vorlage entfernt und das Einleitungsrohr abgespült, ebenso die Glasperlen. Das Destillat wird jetzt mit $2 \mathrm{~g}$ Zinkstaub in einem geräumigen, mittels eines Trichters abgeschlossenen Erlenmeyer während ca. 10 Minuten gekocht, damil die Halogensauerstoffsalze in Halogenide übergehen, und in den Destillationskolben hineinfiltriert. Wiederum werden $10 \mathrm{~g}$ Kaliumbichromat und $20 \mathrm{ccm}$ Schwefelsiure zugefügt und event. mit Wasser auf ca. $200 \mathrm{ccm}$ verdünnt. Die Vorlage wird diesmal mit einer Lösung von 1 bis $2 \mathrm{~g}$ Jodkalium beschickt und mit strömendem Wasser gekühlt; dabel läßt sich bequem ein beliebiges Niveau im Kühlgefă $ß$ innehalten, indem man ein vertikal gestelltes Glasrohr mit der Wasserstrahlpumpe verbindet und das unten einstrümende Wasser oben absaugt. Der Kolbeninhalt wird in 20 Minuten auf ca. $150 \mathrm{ccm}$ eingeengt und noch 20 Minuten unter Einleiten von Wasserdamp $f$ mit verkleinerter Flamme kochend gehalten. Jetzt wird das Destillat mit 0,01 $N$-Thiosulfat litriert.

Bei den Controllversuchen mit bekannten Bromidmengen, welche sorgfältig entbromten Salzproben zugefügt wurden, zeigte sich, daß sich niemals ein zu hoher Wert bei dieser Methode ergibt; die Bromverluste bei den beiden Destillationen übersteigen aber nicht $0,5 \mathrm{mg}$, d. i. auf $10 \mathrm{~g}$ Salz $0,005 \%$. Bei den Wiederholungen stimmten die Analysen auf einige Tausendstel Procente überein.

Bei den Salzanalysen kam auch die Bestimmung des Carnallits im Gemisch in Frage. Dabei wurde die Zusammenstellung der in der Staßfurter KaliIndustrie gebräuchlichen lintersuchungsmethoden* (S. 5) im Prinzip befolgt 3 ). Eine passende Quantität fein zerriebenen Salzgemisches (bei fast reinem Carnallit $2,5 \mathrm{~g}$ )

1) Vgl. für die Abbildung Zeitschr. f. anorg. Chem. 1892, 1, 419.

2) $10 \mathrm{~g}$ reines Chlornatrium schieden beim Destillieren nur $1 \mathrm{ccm} \mathrm{0,01} \mathrm{N}$ Jod in der mit Jodkalium beschickten Vorlage aus, $0,35 \mathrm{mg} \mathrm{Cl}$ war also übergegangen. $10 \mathrm{~g}$ Carnallit ergaben bei einmaliger Destillation eine Abscheidung von 27,12 ccm 0,01 $N$ Jod, bei zweimaliger eine solche von $24,37 \mathrm{ccm}$.

3) Vgl. auch J. und S. Wiernik, Zeitschr. f. angew. Chem. 1893, 43, welche Solenrückstände und $\mathrm{MgCl}_{2}$-haltiges Kochsalz mit absolutem Alkohol auszogen und $\mathrm{Mg}$ und $\mathrm{Cl}$ bestimmten. - Die Methode des Ausziehens mit Alkohol ist von Precht (Zeitschr. f. anal. Chem. 1879, 18, 438) zuerst angegeben. 
Uber d. Krystallisationsschema d. Chlorlde, Bromide, Jodide v. Natrium usw. 369

wurde mit $100 \mathrm{ccm}$ absolutem (nicht $96 \%$ igem) Alkohol 10 bis 15 Minuten tüchtig in einem $250 \mathrm{ccm}$ fassenden Erlenmeyerkolben geschüttelt und 10 oder $20 \mathrm{ccm}$ des alkoholischen Filtrats mit Silbernitrat titriert, unter Verwendung von Kaliumchromat als Indikator. Es liegt hierbei eine Fehlerquelle vor: durch die Auflösung des Chlormagnesiumhydrats wird die Flüssigkeitsmenge sich nämlich etwas über $100 \mathrm{ccm}$ ausdebnen und die Carnallitberechnung etwas zu niedrig ausfallen. Weil umgekehrt auch Steinsalz und Sylvin etwas alkohollöslich sind1) und Spuren von mitanwesendem Tachhydrit und Bischofit als Carnallit berechnet werden, wodurch das Resultat etwas zu hoch würde, ist eine Beseitigung dieser Feblerquelle $z$. B. durch Auswaschen des Salzriickstandes mit absolutem Alkohul und Anfüllen au 200 oder $250 \mathrm{ccm}$ ) nicht versucht worden.

Werden $10 \mathrm{~g}$ Salzgemiseh mit $100 \mathrm{ccm}$ Alkohol extrahiert, und verbrauchen $10 \mathrm{ccm}$ des Filtrats $p \mathrm{ccm} 0,1$ N Silbernitrat, dann ist der $\%$-Gehalt Carnallit $=p \cdot 1,3896$.

Als Belegsanalysen sind diejenigen der reinen Carnallite in der Tabelle auf \$. 384 -385 zu betrachten.

\section{Chemisches Profll der Selzablagerung von der Anhydritregion bis zum grauen Salzton im Berlepsch-Bergwerk, Staßfurt.}

Zur Untersuchung der Bromverteilung in einer unzweifelhaft in einem Zuge abgesetzten Salzfolge, wie diese im Staßfurter Typus der Salzablagerungen vorliegt, wurde ein ganzes Querprofil chemisch aufgenommen. Es wurde dazu eine Stelle im Berlepsch Bergwerk, Staßfurt, gewählt, welche schon früher von Herrn Professor Rinne für einschlägige Untersuchungen mit Meterzahlen versehen war. Das Profil erstreckt sich über $187 \mathrm{~m}$. Von 0 bis $140,5 \mathrm{~m}$ befindet sich die Strecke auf der $394 \mathrm{~m}$-Sohle; der erste Teil des Profils bis zu $91 \mathrm{~m}$ bildet die Wand einer Bergemühle ${ }^{2}$ ). Von $140,5 \mathrm{~m}$ bụs $151 \mathrm{~m}$ (Carnallitregion) wurde das Profil auf einer $6 \mathrm{~m}$ höheren Etage aufgenommen, weil diese Strecke unten abgebaut war; weiter bis $180 \mathrm{~m}$ wieder auf der $394 \mathrm{~m}$-Sohle, wo das Profil eine breite Steinsalzbank in der

Fig. 9.

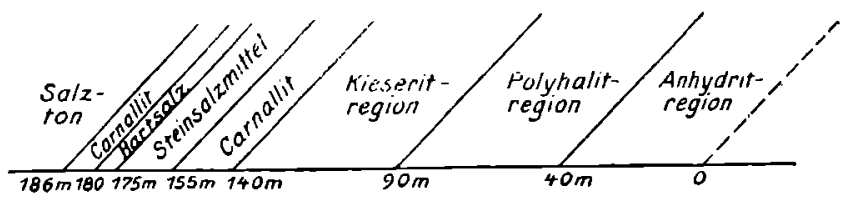

Querprofil im Berlepsch-Bergwerk bei Staßfurt.

Carnallitregion durchquert, und schlielBlich ron $178 \mathrm{~m}$ bis zum Salzton bej $186 \mathrm{~m}$ wieder auf der oberen Etage; in diesem letzten Teile sind Hartsalz
1) Bei $18,5^{0}$ in $100 \mathrm{~g}$ absolutem Alkohol löslich
$K C l \quad 0,034 \mathrm{~g}$, $\mathrm{NaCl} \mathbf{0 , 0 6 5} \mathbf{g}$.

Lobry de Bruyn, Rec. trav. Chim. 1891, 11, 14.

2) Stelle, wo Steinsalz gewonnen wird, zum Ersatz des an anderen Orten abgebauten Kalisalzes.

Groth, Zeitschrift f. Krystallogr. XLV. 
und darüber Carnallit aufgefunden worden. Die Schichten fallen unter ca. $45^{0}$ ein, und die Zahlen auf den beiden Etagen entsprechen sich den Schichten nach genau. In der Fig. 9 sind die ungefähren Ausdehnungen der verschiedenen Regionen angegeben.

Die Proben wurden derart genommen, daß erst die äußere, verwitterte Zone entfernt, und im frischen Salze ein horizontaler Schlitz ausgehackt wurde. Die über eine bestimmte Strecke auf ein Tuch abfallende Menge wurde zerkleinert, gemischt und für sich aufgehoben. Später wurden die Proben in einem Porzellanmörser fein gerieben und noch einmal tüchtig gemischt. Bei den Übergängen auf die höhere Etage wurden auch horizontale Bohrlücher angesetzt und das ausgebohrte Salz gesammelt.

In den Proben wurden Brom-, Chlor- und Carnallitgehalt bestimmt. Die Brombestimmungen wurden häufig wiederholt ausgeführt; stets sind die auffallend hohen oder niedrigen Zahlen durch mehrfache Analyse sichergestellt. Die Chlorbestimmungen wurden ausgeführt, indem $5 \mathbf{g}$ des feingepulverten Gemisches in $500 \mathrm{~cm}$ Wasser gelüst und $10 \mathrm{~cm}$ mit $0,1 N$ Silbernitrat titriert wurden unter Verwendung von Kaliumchromat als Indicator. Die Titrationen wurden immer mehrere Male gemacht. Weil im wesentlichen als Chloride nur Steinsalz und Carnallit vorliegen, wurde der Stein-

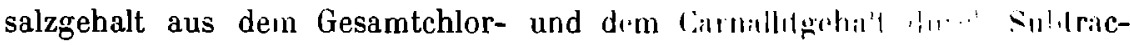
tion ermittelt. Nur dort wo eine größere Menge von sy........nrystallisiert ist, entsteht in dieser Weise ein merklicher Fehler.

(Siehe nebenslehende Tabelle.)

Aus den Zahlen der Tabelle sind verschiedene Schlüsse zu ziehen. Erstens wohl dieser, daß auch das Steinsalz in der Anhydritregion schon merklich brombaltig ist. Bei der Destillation von $50 \mathrm{~g}$ mit Bichromat und Schwefelsäure sieht man im Anfang deutlich die gelbe Farbe der Bromdämpfe im Ableitungsrohre des Destillierkolbens. Nimmt man als specifisches Gewicht des älteren Steinsalzes die Zahl 2,2, so ist bei einem Bromgehalt von $0,013 \%$ schon $1 \mathrm{~kg}$ Brom in $3,5 \mathrm{cbm}$ Salz enthalten. Ein merklicher Chlormagnesium- bezw. Carnallitgehalt findet sich in dieser Region noch nicht vor ${ }^{1}$, das Brom ist als Bromid dem Chlornatrium isomorph beigemischt. - In der Polyhalitregion steigt der Bromgehalt etwas an.

Weiter ins Hangende fängt ein merklicher Carnallitgehalt an aufzutreten, der mit starken Schwankungen in den einzelnen Proben durch die Kieseritregion hindurch anwächst. Nach dem van't Hoffschen Schema würde man einen schroffen Übergang von Kieserit- und Carnallitregion erwarten, also einen plützlich auftretenden hohen Carnallitgehalt. Die Natur

1) Die kleinen in der Tabelle S. 371 angegebenen Carnallitgehaltszahlen in der Anhydritregion sind wohl auf die Alkohollöslichkeit des Stelnsalzes zurückzuführ $n$ (vergl S. 369). 
Über d. Krystallisationsschema d. Choride, Bromide, Jodide v. Natrium usw. 371

\begin{tabular}{|c|c|c|c|c|c|c|c|c|c|}
\hline Nr. & Strecke & $\begin{array}{c}\text { Bro } \\
\stackrel{\ldots}{a} \\
\stackrel{g}{\text { Salz }}\end{array}$ & $\begin{array}{c}\text { n-Bestim } \\
\text { cem } \\
0,01 N \\
\text { Thios. }\end{array}$ & $\begin{array}{c}\text { mung } \\
\text { Gew.- } \\
\text { Proc. } \\
B r\end{array}$ & $\underset{\text { Salz }}{\mathbf{g}}$ & $\begin{array}{l}\text { Gew.- } \\
\text { Proc. } \\
\text { Carn. }\end{array}$ & $\begin{array}{c}\text { Gew.- } \\
\text { Proc. } \\
\text { Cl }\end{array}$ & $\begin{array}{c}\text { Gew.- } \\
\text { Proc. } \\
\mathrm{NaCl} \\
\text { ber. }\end{array}$ & $\begin{array}{l}\text { Brom- } \\
\text { gehalt } \\
\text { auf' } \\
100 \mathrm{~g} \\
\text { Carn. }\end{array}$ \\
\hline 1 & $-\quad 1,5 \mathrm{~m}$ & 50 & 7,95 & 0,013 & 50 & 0,29 & 58,60 & 96,54 & \\
\hline 2 & $15-16,5$ & 50 & 8,67 & 0,014 & & & & & \\
\hline $\mathbf{3}$ & $30-31,5$ & 50 & 8,30 & 0,013 & & & & & \\
\hline 4 & $-51,5$ & 50 & 11,51 & 0,018 & 50 & 0,33 & 57,18 & 94,17 & \\
\hline 5 & $70-71,5$ & 50 & 15,35 & 0,023 & 40 & 0,78 & 31,90 & 85,15 & \\
\hline 6 & $85-86,5$ & 30 & $9,4 z$ & 0,025 & 30 & 4,29 & 56,11 & 89,91 & \\
\hline 7 & $90-91,5$ & 30 & 14,16 & 0,038 & 20 & 6,98 & 54,87 & 86,16 & \\
\hline 8 & $95-96,5$ & & & & 20 & 3,86 & & & \\
\hline 9 & $97,5-99$ & & & & 20 & 2,45 & & & \\
\hline 10 & $100-101,5$ & 30 & 10,00 & 0,027 & 20 & 2,78 & 58,53 & 94,84 & \\
\hline 11 & $102,5-104$ & & & & 30 & 11,61 & & & \\
\hline 12 & $105-106,5$ & 30 & 18,30 & 0,050 & 20 & 13,36 & 45,55 & 66,74 & 0,27 \\
\hline 13 & $107, \mathrm{~s}-109$ & & & & 20 & 8,59 & & & \\
\hline 14 & $110-111,5$ & & & & 20 & 5,78 & & & \\
\hline 15 & $112,5-114$ & 30 & 10,59 & 0,028 & 20 & 4,29 & 57,53 & 92,23 & \\
\hline 16 & $115-116,5$ & & & & 20 & 15,29 & & & \\
\hline 17 & $117,5-119$ & & & & 20 & 14,56 & 51,19 & 75,30 & \\
\hline 18 & $120-121,5$ & 20 & 22,37 & 0,090 & 20 & 23,09 & 36,76 & 46,10 & $\mathbf{0 , 3} \mathbf{3}$ \\
\hline 19 & $122,5-124^{\prime}$ & 20 & 16,36 & 0,065 & 10 & 18,60 & 51,26 & 76,65 & 0,34 \\
\hline 20 & $125-127$ & 20 & 36,02 & 0,144 & 10 & 32,17 & 45,76 & 55,20 & 0,39 \\
\hline 21 & -129 & 20 & 31,52 & 0,126 & 10 & 29,29 & 45,02 & $55,8 z$ & 0,37 \\
\hline 22 & -131 & 20 & 24,28 & 0,097 & 10 & 20,99 & 49,18 & 67,90 & 0,36 \\
\hline 23 & -133 & 20 & 36,34 & 0,145 & 10 & 32,38 & 44,41 & 52,84 & 0,39 \\
\hline 24 & -135 & 20 & 27,10 & 0,108 & 10 & 24,35 & 48,56 & 64,76 & 0,36 \\
\hline 25 & -137 & 20 & 33,68 & 0,135 & 10 & 32,43 & 44,99 & 53,78 & 0,37 \\
\hline 26 & -139 & 10 & 17,15 & 0,197 & 5 & 42,77 & 41,16 & 40,94 & 0,297 \\
\hline 27 & $-140,5$ & $\begin{array}{l}20 \\
10\end{array}$ & $\begin{array}{r}19,41 \\
9,42\end{array}$ & $\begin{array}{l}0,078 \\
0,075\end{array}$ & $\begin{array}{l}10 \\
10\end{array}$ & $\begin{array}{l}17,50 \\
17,43\end{array}$ & 49,53 & 70,71 & 0,38 \\
\hline 28 & $1 \mathrm{g9,5}-140,51)$ & 10 & 15,62 & 0,125 & $\ddot{5}$ & 39,63 & 37,41 & $\mathbf{3 6 , 7 1}$ & 0,295 \\
\hline 29 & $140,5-142$ & 10 & 21,55 & 0,172 & 10 & 53,71 & 38,$2 ;$ & 29,21 & 0,307 \\
\hline 30 & $142^{\prime}-144$ & 10 & 23,21 & 0,186 & $\mathbf{5}$ & 61,37 & 36,37 & 21,27 & 0,295 \\
\hline 31 & -146 & 10 & 21,90 & 0,175 & $\mathbf{5}$ & 64,25 & 39,34 & 24,36 & 0,263 \\
\hline 32 & $146-148$ & 10 & 17,63 & 0,141 & 5 & 50,94 & 38,54 & 31,45 & 0,264 \\
\hline 33 & $148-150$ & 20 & 25,44 & 0,102 & 5 & 35,01 & 47,04 & 55,51 & 0,258 \\
\hline 34 & $150-131,51)$ & 20 & 14,13 & 0,057 & 50 & 0,83 & 46,72 & & \\
\hline 35 & -160 & 50 & 34,15 & 0,0 క̈ & 50 & 0,34 & 55,91 & & \\
\hline 36 & $168-170$ & $\ddot{50}$ & 19,43 & 0,030 & & & 53,44 & & \\
\hline 37 & -180 & 20 & 7,43 & 0,030 & 50 & 0,67 & 43,06 & & \\
\hline 38 & -182 & 20 & 18,60 & 0,074 & 50 & 0,99 & 40,72 & & \\
\hline 39 & $182-184$ & 10 & 14,41 & 0,115 & $\mathbf{5}$ & 53,01 & 35,69 & 25,42 & 0,209 \\
\hline 40 & $184-186$ & 10 & 16,74 & 0,134 & $\mathbf{5}$ & 59,51 & 35,20 & 20,51 & 0,220 \\
\hline 41 & $187-187,6^{1 j}$ & & & & 20 & 1,31 & & & \\
\hline 42 & $\begin{array}{c}\text { Schnüre zw. } \\
83 \text { u. } 87 \text { in }\end{array}$ & & & & 20 & 14,86 & & & \\
\hline 43 & Carnallit-Knolle & & & & 20 & 14,00 & & & \\
\hline 44 & $\begin{array}{c}91 \mathrm{~m} \\
\text { Carnallit }\end{array}$ & 10 & 18,97 & 0,152 & 2,5 & 59,92 & 46,25 & 38,50 & 0,242 \\
\hline & $133-135 \mathrm{~m}$ & 4 & 14,00 & 0,280 & 3,374 & 79,87 & & & 0,35 \\
\hline 45 & Carn. $186 \mathrm{~m}$ & 10 & 24,37 & 0,195 & $\mathbf{2}, \mathbf{5}$ & 78,70 & 38,43 & 13,73 & 0,244 \\
\hline
\end{tabular}

1) Bobrloch. 
hat es offenbar anders gemacht. Weiter unten wird auf die Frage näher eingegangen werden.

Entsprechend der relativ großen Aufnahmefähigkeit des Carnallits in bezug auf Brom geht der Bromgehalt der Mischproben mit dem Carnallit-

Fig. 10.

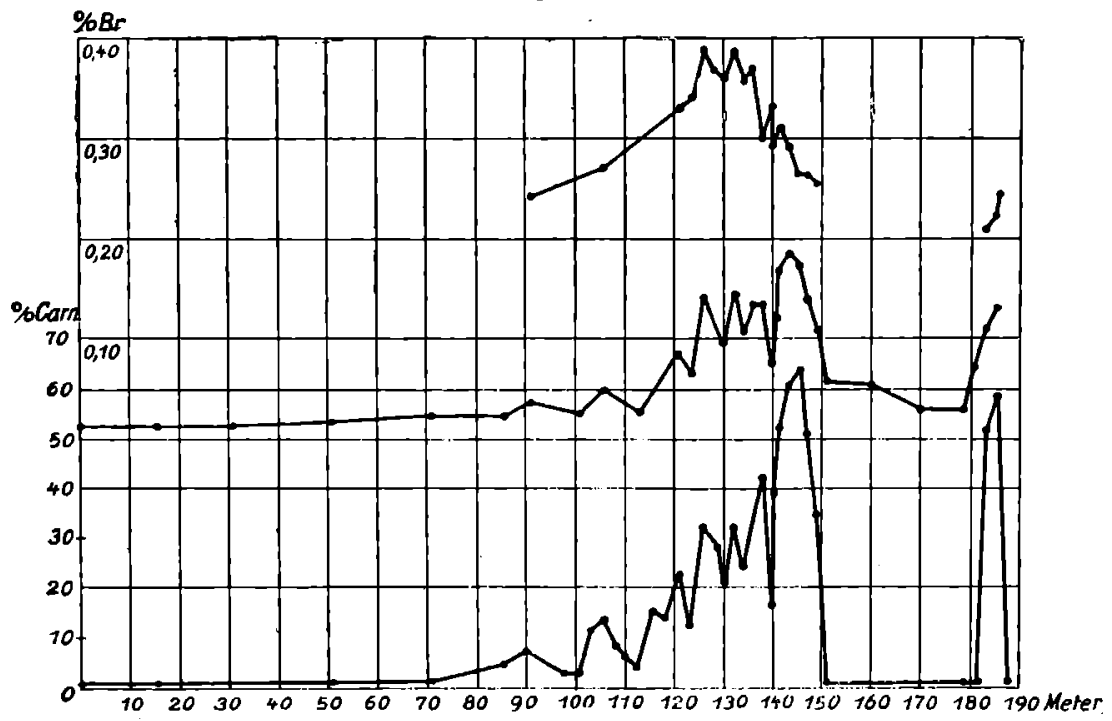

Berlepsch-Profil, Carnaliitcurve (untere), Bromcurve (ynitllere), Brom aul $100 \mathrm{~g}$ Carnallit (obere).

gehalt auf und ab. In der letzten Spalte der Tabelle ist der Bromgehalt auf $100 \mathrm{~g}$ Carnallit berechnet unter Annahme, daß das Steinsalz einen Bromgehalt von $\frac{1}{12}$ desjenigen vom Carnallit besitzt (Tabelle auf S. 367). Man sieht hieraus, daß der Carnallit in der Kieseritregion regelmäßig stärker bromhaltig ist als in der eigentlichen Carnallitregion. Sogar tritt in der oberen Curve der Fig. 10 für den Bromgehalt auf $100 \mathrm{~g}$ Carnallit ein deutliches Maximum heraus. Daß die stärkere Bromführung in der Kieseritregion nicht auf einen Sylvingehalt zurückzuführen ist (obgleich gelegentlich Sylvin daselbst vorgefunden wurde $\left.{ }^{1}\right)$ ), beweist der Versuch Nr. 4h. Es wurde der Carnallit aus der Probe 133-135 m mittels Acetylentelrabromid als schwerer Flüssigkeit abgetrennt und für sich analysiert, nachdem das Tetrabromid durch sehr häufiges Ausschütteln und Auswaschen mit Benzol und Äther vollständig entfernt war. Dieser Carnallit zeigte sich relativ stark bromhaltig und stimmt im Bromgehalt mit der aus der ganzen Mischprobe berechneten Zahl überein.

Die Carnallitregion ist im vorliegenden Profile nur teilweise ausgebildet,

1) Vergl. van't Hoff Oz. Salzabl. I. 8:5. 
weil eine dicke Steinsalzbank zwischen gelagert ist. Im Contact mit Carnallit befindet sich im Steinsalzmittel eine Zone mit 0,05\% Bromgehalt, welcher auf Sylvinführung schließen ließ; in der Tat zeigte die Probe $158-160 \mathrm{~m}$ einen Sylvingehalt von ca. 8\%. Einen geringen Sylvingehalt im ganzen Steinsalzmittel erwähnt Everding $\left.{ }^{1}\right)$.

Kurz vor der Abscheidung der grauen Salztondecke sind auch aus diesem Steinsalzmittel, das wohl als das Resultat einer localen Überflutung des Kalimutterlagers resp. einer Verdünnung der über dem Iager stehenden Mutterlauge zu betrachten ist, noch Mutterlaugensalze auskrystallisiert, zuerst Hartsalz von einigen Metern Mächtigkeit, dann Carnallit. Der Übergang in die Carnallitregion ist hier ganz schroft. Weil unter dem Hartsalz Langbeinil führendes Salz angetroffen wurde, ist der Krystallisationsgang mit dem van 't Hoffschen I)iagramm ohne Kalksalze für $83^{\circ}$ Fig. 12 S. 376 (Oz. Salzabl. I, Fig. 30, 'Tal. II) vollkommen im Einklange und wird dort ungefähr durch $Y \operatorname{TS}() \%$ dargeslellt.

Aulfallend isl die Tatsuche, daß der relativ jüngere Carnallit weniger bromhaltig ist als der iltere.

Besonders sei noch erwähnt, daß bei $91 \mathrm{~m}$, also auf der Grenze der Polyhalit- und Kieseritregion eine im Steinsalze eingewachsene Knolle (ca. $8 \mathrm{~cm}$ Durchmesser) von rolem Carnallit ${ }^{2}$ ) vorgefunden wurde. Die Analyse desselben ist in der Tabelle unter $\mathrm{Nr}$. 43 angegeben. Ehenso wurde eine herauspräparierte Carnallitprobe bei $186 \mathrm{~m}$ für sich analysiert.

\section{Chemische Profile durch Salzablagerungen von Salzdetfurth.}

Fin ununterbrochenes Querprofil der älteren Carnallitablagerung und ebenso des descendenten Sylvinits und Carnallits wurde im Bergwerke Salzdetfurth aufgenommen. Ein Schema des lagers ist in Fig. 11 angegeben. Ob im älteren Steinsalze eine Polyhalit- und Kieseritregion sich vorfinden, ist bis jetzt noch nicht untersuchl worden. Jedenfalls sind die üblichen Jahresringe vorhanden. Das altere Carnallilprolil wurde mittels acht Mischproben über je $5 \mathrm{~m}$ aufgenommen beim Schachle am Nordflügel des sogen. südlichen Qucrschlages auf der $700 \mathrm{~m}$-Sohle. Die Schichten fallẹn an dieser Stelle ungefähr senkrecht ein.

Jas Profil im jüngeren Kalisalzlager befand sich im Südostfclde auf der $700 \mathrm{~m}$-Sohle, Untersuchungsquerschlig $85 \mathrm{~m}$ üstlich vom blinden Schachte II ${ }^{2}$.

Fig. 11.

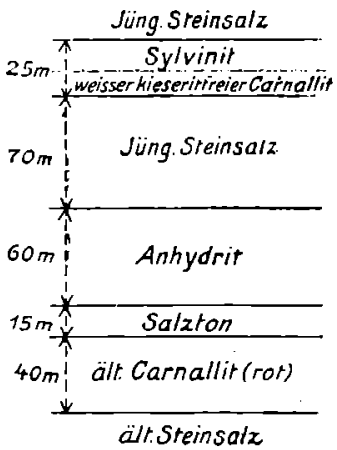

Layerungssichema, Salzdetrurth.

1) In Deulschlands Kalibergbau 1907, 76.

2) Vergl. Precht-Ehrlardt, Norddeutsche Kalindustrie 6. Aufl., 1906. 18. 
Die Analysenergebnisse sind die nachfolgenden:

\begin{tabular}{|c|c|c|c|c|c|c|c|c|c|c|}
\hline \multirow[b]{2}{*}{ Nr. } & \multirow{2}{*}{\multicolumn{2}{|c|}{ Strecke }} & \multicolumn{3}{|c|}{ Brombestimmung } & \multicolumn{2}{|c|}{$\begin{array}{c}\text { Carnallit- } \\
\text { bestimmung }\end{array}$} & \multirow{2}{*}{$\begin{array}{l}\text { Gew.- } \\
\text { Proc. } \\
\text { Chlor }\end{array}$} & \multirow{2}{*}{$\begin{array}{c}\text { Gew.- } \\
\text { Proc. } \\
N^{\top} a C l \\
\text { berechn. }\end{array}$} & \multirow{2}{*}{$\begin{array}{c}\text { Brom- } \\
\text { gehalt aul } \\
100 \mathrm{~g} \\
\text { Carnallit }\end{array}$} \\
\hline & & & $\mathrm{gSalz}$ & $\begin{array}{l}\operatorname{ccm} 0,01 \mathrm{~N} \\
\text { Thiosulfat }\end{array}$ & $\begin{array}{l}\text { Gew:- } \\
\text { Proc. } \\
B r\end{array}$ & $g$ Salz & $\begin{array}{l}\text { Gew.- } \\
\text { Proc. } \\
\text { Carn. }\end{array}$ & & & \\
\hline 1 & 0 - $\mathrm{m} \mathrm{m}$ & & 10 & 16,34 & 0,131 & 5 & 36,29 & 40,37 & 43,70 & 0,328 \\
\hline z & $5-10$ & 눈 & 10 & 26,62 & 0,213 & 5 & 58,98 & 36,86 & 23,58 & 0,350 \\
\hline 3 & $10-15$ & $\equiv$ & 10 & 30,8 & 0,247 & 5 & 62,87 & 36,40 & 20,36 & 0,382 \\
\hline 4 & $15-20$ & & 10 & 28,86 & 0,231 & $\ddot{3}$ & 60,13 & 35,58 & 20,73 & 0,373 \\
\hline 5 & $20-23$ & E & 10 & 26,76 & 0,214 & $\ddot{3}$ & 54,78 & 31,94 & 18,12 & 0,380 \\
\hline 6 & $25-30$ & త్ర & 10 & 26,49 & 0,212 & 5 & 64,48 & 37,61 & 21,36 & 0,320 \\
\hline 7 & $30-35$ & $\dot{ \pm}$ & 10 & 30,89 & 0,247 & 5 & 69,07 & 37,56 & 18,39 & 0,350 \\
\hline 8 & $\begin{array}{l}3.3-40 \\
\text { Salzton }\end{array}$ & & 10 & 21,54 & 0,172 & 5 & 50,08 & 40,37 & 35,00 & 0,324 \\
\hline 9 & $0-4 \mathrm{~m}$ & $\geq$ & 10 & 30,04 & 0,240 & 2,5 & 80,81 & 43,10 & $20,101\}$ & $0,2 !$ \\
\hline 10 & $4-8$ & $5 \overline{0}$ & 10 & 31,77 & 0,254 & 2,5 & 82,66 & 42,78 & $18,40 \mathrm{~d}$ & 0,301 \\
\hline 11 & $8-12$ & $\mathcal{S}$ & 10 & 29, & 0,236 & $2, \ddot{z}$ & 80,50 & 43,25 & $20,541)$ & 0,287 \\
\hline 12 & $12-15$ & & 10 & 14, & 0,114 & 50 & 4,32 & 53,59 & - & - \\
\hline 13 & $15-13$ & & 20 & 30, & 0,122 & 50 & 0,53 & 53,63 & - & - \\
\hline 14 & $19-23$ & 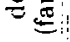 & 20 & 26,17 & 0,105 & 50 & 0,58 & 55,26 & $\tau$ & - \\
\hline
\end{tabular}

Die Schlüsse aus den obigen Zablen sind in den Abschnitten V und VI angeführt.

\section{Die $\nabla a n ' t$ Hoffschen Versuchsergebnisse im Vergleiche mit den natürlichen Vorkommnissen.}

An der Hand der oben mitgeteilten Daten ist es von Interesse zu untersuchen:

1. inwieweit die Ergebnisse mit dem van't $H$ offschen Schema übereinstimmen;

2. ob die Salztonbildung kurz oder lange vor der Bischofitausscheidung stattgefunden hat, ob also die primäre Staßfurter Carnallitregion bei normaler Krystallisation bis zum Schlusse eine bedeutend größere Mächtigkeit gezeigt hätte;

3. wie die Bromgehaltszahlen zu deuten sind in Hinsicht auf die Krystallisationsergebnisse im ersten Teile dieser Arbeit.

Bei der Besprechung der beiden ersten Fragen werden vorwiegend die Kieserit- und Carnallitregion in Betracht gezogen werden, weil sie zur Discussion genügen; nach $v$ an ' $t \mathrm{H}_{0} \mathrm{ff}^{2}$ ) ist für $25^{0}$ bei anfangender Magne-

1) Die drei Proben des farblosen descendenten Carnallits waren ohne Rüickstand in Wasser löslich und enthielten kein Sulfat (Kieserit). Daß der Gehalt Carnallit + Steinsalz über $100 \%$ steigt, ist wohl so zu erklären, daß etwas Bischofit bezw. Tachhydrit mit als Carnallit in Rechnung gebracht wird.

2) Zeitschr. f. anorg. Chem. 1905, 47, 277. Ausz. diese Zeitschr. 44, 317. 
Über d. Krystallisationsschema d. Chloride, Bromide, Jodide v. Natrium usw. 375 siumsulfatausscheidung schon $97,50_{10}^{\circ}$ des ursprünglich vorhandenen Calciums ausgesondert, in der Kieserit- und Carnallitregion braucht das Calcium danach nicht mehr berücksichtigt zu werden.

In dem natürlichen Vorkommen ist die Zusammensetzung nach Gewichtsprozenten im Mittel nach meinen Bestimmungen, sowie nach den Analysen von Bischof, Precht, Kubierschky u. a.:

\begin{tabular}{l|c|c|c}
\hline & Steinsalz & Kieserit & Carnallit \\
\hline Kieseritregion & $65 \%$ & $20 \%$ & $15 \%$ \\
Carnallitregion & 20 & 20 & 60
\end{tabular}

Von van't Hoff ist für die Ausscheidung in molekularen Mengen bei $25^{0}$ die folgende Tabelle zusammengestellt ${ }^{1}$ ).

\begin{tabular}{l|c|c|c|c|c}
\hline & Steinsalz & Kieserit & Kainit & Carnallit & Bischofit \\
\hline Alteres Steinsalz & 95,4 & - & - & - & - \\
Kieseritregion & 4,42 & 1,05 & 2,02 & - & - \\
Carnallitregion & 0,03 & 0,35 & - & 0,1 & - \\
Schlußausscheid. & 0,45 & 0,38 & - & 0,08 & 7,62
\end{tabular}

In Gewichtsprozente umgerechnet ergibt diese Tabelle:

\begin{tabular}{l|c|c|c|c|c}
\hline & Steinsalz & Kieserit & Kainit & Carnallit & Bischofit \\
\hline \hline Kieseritregion & $\mathbf{2 8 , 5} \%$ & $16 \%$ & $\mathbf{5 5 , 5} \%$ & - & - \\
Carnallitregion & 2,25 & 62,1 & - & $\mathbf{3 5 , 6} \%$ & - \\
Schlußausscheid. & 0,54 & 3,2 & - & 1,4 & $\mathbf{9 4 , 9 0 \%}$
\end{tabular}

Wie bereits van't Hoff hervorgehoben hat, ist das natürliche Vorkommen mit dem Krystallisationsschema für $25^{\circ}$ nicht im Einklange, es müßte das Salzgemisch in der Kieseritregion zu mehr als der Hälfte aus Kainit beslehen, während Kainit in den primären Lagerstätten nicht auftritt. Dem ist als weiteres Zeichen einer Abweichung hinzuzufügen, daß die Zusammensetzung in der Carnallitregion von den experimentellen Zahlen für $25^{0}$ stark abweicht.

Deshalb wurden aus den Daten von van't Hoff die absoluten und relativen Ausscheidungen auch für $8^{\circ}$ berechnet. Geht man mit van 't H of $f$ aus von einer Lüsung

$$
1000 \mathrm{H}_{2} \mathrm{O} \quad 100 \mathrm{NaCl} \quad 2,2 \mathrm{KCl} \quad 7,8 \mathrm{MgCl}_{2} \quad 3,8 \mathrm{MgSO}_{4},
$$

1) Oz. Salzabl. 1905, 1, 74. 
so wird das Loeweïtfeld getroffen in $\alpha$, und fängt die Kieseritausscheidung an in der Mitte zwischen den Punkten $K$ und $Y$ in Fig. 12. Die Zusam-

Fig. 18.

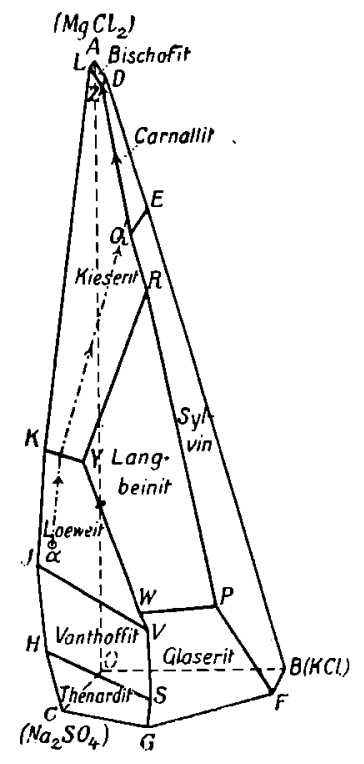

Krystallisationsschema der Salzablagerungen bel $83^{0}$ (ohne Kalksalze) nach van't HoIf. mensetzung der Lüsung findet sich durch Interpolation zwischen $K$ und $Y$ zu

$$
\begin{aligned}
& 1000 \mathrm{H}_{2} \mathrm{O} \quad 34 \mathrm{NaCl} \quad 10,5 \mathrm{KCl} \quad 43,5 \mathrm{MgCl}_{2} \\
& \text { 12,5 } \mathrm{MgSO}_{4} \text {. }
\end{aligned}
$$

Nehmen wir an, daß alles Chlormagnesium bis dahin in Lösung geblieben ist, so wird

$$
100 \mathrm{NaCl} \quad 7,8 \mathrm{MgCl}_{2} \text { usw. }
$$

zu $a\left(34 \mathrm{NaCl} \quad 43,5 \mathrm{MgCl}_{2}\right.$ usw.), also $a=\frac{7,8}{43,5}$,

Chlornatriumrest in der Lösung $34 a=6,1$, Chlornatriumausscheidung $100-6,1=93,9$.

IIiernach würde $93,9 \%$ des Steinsalzes schon im Liegenden der Kieseritregion ausgeschieden sein.

Die Annahme, daß das Chlormagnesium in unveränderter Menge in Lösung bleibt, trifft nicht ganz zu, weil die Ausscheidung von Polyhalit $\left(\mathrm{K}_{2} \mathrm{SO}_{4} \cdot \mathrm{MgSO}_{4} \cdot 2 \mathrm{CaSO}_{4} \cdot 2 \mathrm{H}_{2} \mathrm{O}\right)$ und Loeweït $\left(2 \mathrm{Na}_{2} \mathrm{SO}_{4} \cdot 2 \mathrm{MgSO}_{4} \cdot 5 \mathrm{H}_{2} \mathrm{O}\right)$ eine Umsetzung von $\mathrm{KCl}$ bezw. $\mathrm{NaCl}$ mit $\mathrm{MgSO}_{4}$ unter Bildung von $\mathrm{K}_{2} \mathrm{SO}_{4}$ hezw. $\mathrm{Na}_{2} \mathrm{SO}_{4}$ und $\mathrm{MgCl}_{2}$ erfordert. Der Chlormagnesiumgehalt nimmt dadurch etwas zu, und $a$ ist etwas zu klein berechnet, dementsprechend die Zahl 93,9\% etwas zu groß.

Betrachten wir weiter die Kieserit- und Carnallitregion nach den va n't IHof fschen Angaben für 830. Die Lüsung

$$
1000 \mathrm{II}_{2} \mathrm{O} \quad 34 \mathrm{NaCl} \quad 10,5 \mathrm{KCl} \quad 43,5 \mathrm{MgCl}_{2} \quad \text { 12,5 } \mathrm{MgSO}_{4} \text {, }
$$

geht in der Kieseritregion unter Kieserit- und Steinsalzausscheidung über in eine Lüsung auf der Linie Q\% (1'ig. 12); der darstellende Punkt dieser Lösung muß ein Verhältnis $\mathrm{KCl}: \mathrm{MgCl}_{2}=10,5: 43,5$ aufweisen, liegt also auf etwa 0,1 der Strecke ()$Z$ von $(Q$ entfernt und hat die $Z u-$ sammensetzung

$$
1000 \mathrm{H}_{2} \mathrm{O} \quad 4 \mathrm{NaCl} \quad 22 \mathrm{KCl} \quad 89,5 \mathrm{MgCl}_{2} \quad 4,5 \mathrm{MgSO}_{4} \text {. }
$$

Unter Verbleib des Chlormagnesiums in Lösung wird:

$7 . \mathrm{u}$

$$
\begin{aligned}
& b\left(4 \mathrm{NaCl} \quad 89,5 \mathrm{MgCl}_{2} \quad 4,5 \mathrm{MgSO}_{4} \text { usw.), also } b=\frac{43,5}{\mathbf{8 9 , 5}}\right. \\
& \text { Chlornatriumrest in Lösung } \quad 4 b=2,0 \\
& \text { Kieseritrest in Lösung } \quad 4, ; b b=2,2
\end{aligned}
$$


Uber d. Krystallisationsschema d. Chloride, Bromide, Jodide v. Natrium usw. 377

$$
\begin{array}{ll}
\text { Chlornatriumausscheidung } & 34-2,0=32 \\
\text { Kieseritausscheidung } & 12,5-2,2=10,3 .
\end{array}
$$

In der Carnallitregion wird die ursprüngliche Lösung unter Ausscheidung von Steinsalz, Kieserit und Carnallit zu

$$
c\left(\begin{array}{lllllll}
1000 \mathrm{H}_{2} \mathrm{O} & 2 \mathrm{NaCl} & 4 \mathrm{KCl} & 116 \mathrm{MgCl}_{2} & 1 \mathrm{MgSO}_{4}
\end{array}\right) \text { (Z). }
$$

Sei die Carnallitausscheidung $x$, dann ist

$$
\begin{array}{rlrl}
c 4+x=10,5 & c 116+x=43,5, \\
c=\frac{33}{112} & x=9,3
\end{array}
$$

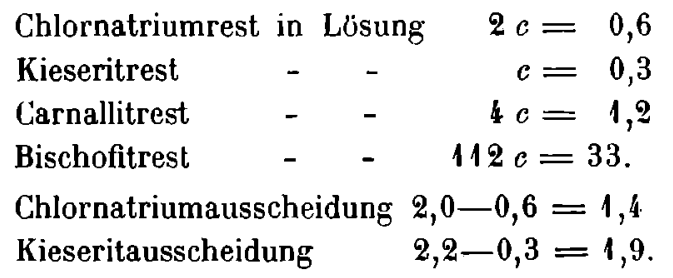

Zusammenfassend ergibt sich für $83^{\circ}$ :

\begin{tabular}{l|c|c|c|c}
\hline & Steinsalz & Kieserit & Carnallit & Bischofit \\
\hline Kieseritregion & $=\ldots$ & 10,3 & - & - \\
Carnallitregion & 32 & 1,9 & 9,3 & - \\
SchluBausscheidung & 1,4 & 0,3 & 1,2 & 33 \\
& 0,6 & 12,3 & 10,5 & 43,5 \\
& 34 & $\mathrm{NgSO}$ & $\mathrm{KCl}$ & $\mathrm{MgCl}_{3}$
\end{tabular}

oder in Gewichtsprozenten:

\begin{tabular}{l|c|c|c|c}
\hline & Steinsalz & Kieserit & Carnallit & Bischotit \\
\hline Kieseritregion & $57 \% / 0$ & $43 \%$ & - & - \\
Carnallitregion & 2,8 & $\mathbf{9 , 0}$ & $\mathbf{8 8 , 2} \%$ & - \\
Schlußausscheidung & 0,3 & $\mathbf{0 , 6}$ & $\mathbf{5}$ & $\mathbf{9 4 0} / 6$
\end{tabular}

Man sieht, daß die Zahlen für $83^{\circ} \mathrm{mil}$ dem natürlichen Vorkommen sehr viel besser übereinstimmen als diejenigen für $25^{\circ}$. - Sehr auffallend ist es aber immer noch, daß der Steinsalzgehalt in der Carnallitregion nach dem van't Hoffschen Schema nur 2,25 bezw. $2,8 \%$ beträgt bei $25^{\circ}$ und $83^{\circ}$, während im natürlichen Vorkommen immer ca. $20 \%$, also eine sehr viel größere Menge, gefunden wurden. Eine andere ursprüngliche Zusammensetzung des Salzgemisches kann dafür keine Erklārung geben; dadurch wären nur die vorhergehenden Ausscheidungen anders, sobald es aber zur Carnallitabsonderung kommt, muß immer dieselbe Krystallisationsbahn zurückgelegt werden. 
Die reichlichere Ausscheidung des Steinsalzes in der natürlichen Carnallitregion würde aul eine sehr viel größere Löslichkeit des Chlornatriums in der chlormagnesiumreichen Lösung, als aus den van 't $\mathrm{H}$ of fschen Zahlen hervorgeht, hindeuten. Die Löslichkeit von Chlornatrium in an Carnallit bezw. Bischofit gesältigten Lösungen ist aber bei den van't Hoffschen Arbeiten in sehr vielen Fällen $\left.{ }^{1}\right)$ bestimmt und immer entsprechend klein befunden. Damit ist die sichere Basis für alle Schlußfolgerungen gegeben. - Auch die Endlaugen der Chlorkalium-Fabrikation, welche an Chlornatrium gesättigt sind, enthalten, übereinstimmend mit den va n ' $t$ Hoffschen Daten, weniger als $1 \% \mathrm{NaCl}^{2}$ ).

Es wäre noch möglich, daß in den Lagerstätten nur der anfängliche Teil der Carnallitregion vorliegt, während der berechnete Steinsalzgebalt von 2,8\% für die ganze Region his zur Bischofitausscheidung gilt. Deshalb wurde aus den van't Hoffschen Daten für $\mathbf{8 3}^{\circ}$ berechnet, wie hoch der Steinsalzgehalt in der letzlen Hälfte der Carnallitregion ist. Die Lösung, welche in der Mitte zwischen $Q$ und $Z$ vorliegt, enthält:

und wird zu

$$
1000 \mathrm{H}_{2} \mathrm{O} \quad 3 \mathrm{NaCl} \quad 14 \mathrm{KCl} \quad 101 \mathrm{MgCl}_{2} \quad 3 \mathrm{MgSO}_{4}
$$

$$
\begin{array}{ccc}
d\left(1000 \mathrm{H}_{2} \mathrm{O} \quad 2 \mathrm{NaCl}\right. & 4 \mathrm{KCl} & \left.116 \mathrm{MgCl}_{2} \quad 1 \mathrm{MgSO}_{4}\right) . \\
d 116+x=101 & d 4+x=14 \\
d=\frac{87}{112} & x=10,9 . \\
\text { Chlornatriumrest in Lösung } 2 d=1,55 \\
\text { Kieseritrest } \quad-\quad-\quad d=0,78 \\
\text { Chlornatriumausscheidung } 3-1,55=1,45 \\
\text { Kieseritausscheidung } & 3-0,78=2,22 .
\end{array}
$$

In Gewichtsprozenten:

$$
\begin{array}{ccc}
\text { Steinsalz: } & \text { Kieserit: } & \text { Carnallit: } \\
2,5 \% & 9,0 \% & \mathbf{8 8 , 5} \% .
\end{array}
$$

Innerhalb der Carnallitregion ist also fast keine Änderung in der $\mathrm{Zu}$ sammensetzung $\mathrm{zu}$ verzeichnen.

Nach dem Vorhergehenden ist es klar, daß der bedeutende Carnallitgehalt der natürlichen Kieserit- und der relativ hohe Steinsalzgehalt der Carnallitregion keine Gleichgewichtserscheinungen in dem Sinne der Laboratoriumsversuche sein künnen. Als eine Erklärung der Abweichung zwischen den Schlußfolgerungen nach dem van't Hoffschen Schema und den Beobachtungen in der Natur kann das Folgende gelten:

1) Oz. Salzabl. 1, S. 35: bei $25^{0}$ Punkt $A, D, E, L, Q, R$ und $Z$; S. $60:$ bei $83^{0}$ Punkt $A, D, E, L, Q$ und $Z$.

2) E. Erdmann, in Deutschl. Kalibergbau 1907, 119. 
In eintrocknenden Salinen hat man beobachtet, daß die unteren Schichten der Lauge salzreicher sind als die oberen ${ }^{1}$ ). Ähnlich wird auch die Mutterlauge beim Eindampfen des Zechsteinmeeres in den unteren Schichten concentrierter, d. h. in diesem Falle chlormagnesiumreicher gewesen sein können, als die oberflächlichen Partien. Nun ist nach den Bestimmungen von Precht und Wittjen ${ }^{2}$ ) die Löslichkeit von Steinsalz in einer $20 \%$ igen Chlormagnesiumlösung zwischen $10^{\circ}$ und $100^{\circ}$ ca. $6 \%$ $\mathrm{NaCl}$, also mehr als $6 \mathrm{mal}$ so groß als die Löslichkeit des $\mathrm{NaCl}$ in einer ca. $25 \%$ igen $\mathrm{MgCl}_{2}$-Lösung (Sättigung an Carnallit). Wenn sich nun aus verschiedenen Tiefen der Mutterlauge infolge von Temperaturwechsel und Verdunstung des Wassers gleichzeitig Salz ausscheidet, so werden die unteren Schichten Carnallit (mit wenig Steinsalz und Kieserit), die oberen nur Steinsalz mit Kieserit absondern können. Das jetzt verfestigt vorliegende Resultat kann danach als das gemeinsame Ergebnis der beiden örtlich gesonderten Krystallisationen angesehen werden. So erklärt sich 1) das Auftreten von Carnallit schon auf der Grenze der Polyhalit- und Kieseritregion, 2) das allmähliche Ansteigen des Carnallitgehaltes innerhalb der Kieseritregion, 3) der hohe Steinsalz- und Kieseritgehalt in der Carnallitregion.

Im übrigen werden die vielen Fragen der Gleichgewichtsstörungen z. B. die relative Geschwindigkeit beim Absinken der auskrystallisierten Salze und die Resorptionen durch Temperatur- und Concentrationsunterschiede in den verschiedenen Schichten, wohl häufig einen großen Einfluß auf das Endresultat ausgeübt haben. Desto wertvoller ist der von van 't H of f in seinen Gleichgewichtsdiagrammen gegebene Schlüssel für das Verständnis.

In bezug auf die Mächtigkeit der Carnallitregion nach dem van 't Hoffschen Schema für $8^{\circ}$ geht aus den Tabellen auf S. 377 hervor, daß für die Gewichtsmengen die Beziehung besteht:

$$
\frac{\text { Menge Carnallitregion }}{\text { Menge Kieseritregion }}=\frac{1,4}{32} \cdot \frac{57}{2,8}=0,89 \text {. }
$$

Nimmt man als spec. Gewicht für Carnallit, Steinsalz und Kieserit resp. 1,6, 2,2 und 2,6 an, so ergibt sich für die theoretische Carnallitregion eine $1,2 \mathrm{mal}$ größere Müchtigkeit als diejenige der theoretischen Kieseritregion. Im natürlichen Vorkommen ist die Carnallitregion nicht zur vollständigen Entwickelungr gelangt. Die Salzt on decke hat sich abgelagert, ehe die Concentration der Bischofitausscheidung erreicht war, denn eine größere primäre Bischofitablagerung ist keinerorts aufgeschlossen ${ }^{3}$ ). Das

1) Vergl. 0z. Salzabl. 1, 85 unten.

2) Berl. Ber. 1881, 14, 1673.

3) Schichten von Bischofit zwischen Carnallit und Salzton werden gelegentlich erwähnt (vergl. E. Erdmann, in Deutsch. Kalibergbau 1907, 9). Auch im Salzton ist es örtlich zur Bischofitausscheidung gekommen, weil $\mathrm{Zimmermann}$ (Monatsberichte der deutschen geol. Ges. 1907, 59, 138) angibt, daß der wässerige Auszuc 
bekannte Bischofitvorkommen im Bergwerk Hercynia, Vienenburg, ist am Liegenden und am Hangenden von Carnallit begrenzt und nach der Ansicht des Herrn Director Feitl) eine Spaltenausfüllung.

Aus den Daten läßt sich schätzungsweise berechnen, ein wie großer Teil der vollständigen Carnallitregion im Staßfurter Bezirk vorliegt. Wenn man die Grenze zwischen Kieserit- und. Carnallitregion in dem Horizont annimmt, wo der Carnallitgehalt des Salzgemisches von ca. $35 \%$ auf ca. $60 \%$ steil ansteigt, so verhalten sich die Mächtigkeiten der Kieserit- und Carnallitregion in dem von mir untersuchten BerlepschProfil ungefähr wie $35 \mathrm{~m}: 31,5 \mathrm{~m}$ (vgl. Fig. 9, S. 369 unter l3erücksichtigung des Finfallwinkels von $45 \%$. Die obengenannte Verhältniszahl der theoretischen Kieseritregion zur vollständigen Carnallitregion würde hingegen auf relative Mächtigkeiten von $35 \mathrm{~m}: 12 \mathrm{~m}$ schließen lassen. Mithin würde in dem in liede stehenden Staßfurter Profil nur $3{ }_{4}^{3}$ der vollständigen Carnallitregion vorliegen. Jas ließe sich folgendermaßien crklïren. Entweder ist die ältere Zechsteinablagerung bis zur Bischofitkrystallisation vorangeschritten gewesen, und die Bischofilregion zusammen mit $1 \frac{1}{4}$ der Carnallitregion fortgewachsen, che die Salztonablargerung einsetzle, oder es hat sich der Salzton sedimentiert, als crst $\frac{3}{4}$ der (arnallitregion auskrystallisiert war. Die teilweise limkrystallisation (Bildung descendenter Salze) der Staßfurter Ablagerung und die Ingerung des Salztones ïber diesen alten descendenten Salzen macht die erste $\Lambda$ uflassung wahrscheinlicher.

Jie Schlußausscheidung helrägt $\begin{aligned} & 0,6 \\ & 1,4\end{aligned} . \underset{0,5}{2,8}$ mal die Gewichtsmenge der Carnallitregion. Eine Rechnung ähnlich derjenigen auf S. 376 ergibt, daß auf $100 \mathrm{~g}$ SchluBausscheidung $23 \mathrm{~g}$ Wasser verdampft sein muß. Dic Menge Endlauge ist also 3,0 mal die Menge Carnallitregion, und weil das spec. Gewicht einer gesiitligten ('hlormagnesiumlösung 1,4 belrägt, muß dic 'Jiefe des Mceres boi anfangender Bischolitausscheidung noch 3,6 mal die Mächtigkeit der abgclagerten Carnallitregion sein. (Bei einer Carnallitregion von $40 \mathrm{~m}$ also immerhin $144 \mathrm{~m}$.) Diese Endlauge wird wohl zum 'Teil in den Multerlaugen der jüngeren Salzbildungen festgrelegt und sonst schließlich in den Ozean gelangt sein. Auch wenn dic Kahl von ca. $150 \mathrm{~m}$ mit den natürlichen Verhällnissen nicht quantitativ ïbereinstimmt, kann doch von einer "J'rockenlegung " des Kalimutterlagers vor der Salztonablagerung ${ }^{2}$ ) nicht die Rede sein, ausgenommen örllich infolge von llebungen oder am Rande durch Schrumpfung der Laugenmenge nach

eines trockenen Salztones beim Verdunsten direct Carnallit auskrystallisieren lißßt. Diesces ist nur mögliçh, wenn neloen Carnallit auch Bischofit im Salzton vorhanden war.

1) Briefliche Milleilung.

2) Vergl, Everding, in Deutschl. Killibergbau 60, 89 
Uber d. Krystallisationsschema d. Chloride, Brolnide, Jodide v. Natrium usw. 381

der Mitte zu. Der graue Salzton ist also sehr wahrscheinlich als eine Flachseeablagerung anzusprechen. Das Material könnte zum Teil aus der fortgewaschenen Bischofitregion stammen. Für den reichlichen Magnesiumcarbonatgehalt im oberen Salzton ist diese Herkunft aber nicht anzunehmen. Auch deuten die von Zimmermann ${ }^{1}$ j im mittleren Salzton entdeckten marinen Versteinerungen auf eine zeitliche Verdünnung der Lauge über dem unteren Salztone, wohl infolge eines erneuten Meereseinbruches, hin.

Schließlich wurde auf S. 347 die Frage gestellt, wie die Bromgehaltszahlen des Carnallits im Staßfurter und Salzdetfurther Profil, welche ersichtlich je ein Maximum bilden, zu deuten seien. Weil die sich ausscheidenden Krystalle nach den Krystallisationsversuchen einen kleineren relativen Bromgehalt aufweisen als die coexistierende Lösung, so müßte sich das Brom in der Lauge anhäufen und demzufolge auch in den Krystallen ständig zunehmen. Als Anhalt dafür, daß auch die natürliche Lange relativ stark bromhaltig ist, war eine von Herrn Jirector Simon mir freundlichst zur Verfügung gestellte sog. Urlauge ron Aschersleben äußerst wertvoll. Sie zeigte spektroskopisch einen bedeulenden Lithiumgehalt ${ }^{2}$ ), welcher noch bei $9: 30$ facher Verdünnung gut sichtbar war, und enthielt $0,496 \% \mathrm{Br}$ (Niltel aus 0,302 und $0,494 \%$ gegen $24,57 \% \mathrm{Cl}$, also $Q_{1}=0,73$. In Ilinsicht aul' den Chlorgehalt kann die Lauge als fast gesättigt betrachtet werden. Nach der Tabelle auf S. 367 müßle der Carnallit, welcher mit dieser Lüsung coexistieren kann, 0,204\% $\mathrm{Br}$ enthalten.

Ls läßt sich berechnen, wie der Bromgehalt in der Carnallitregion zum Hangenden hin zunehmen müßte. Nach den Zahlen auf S. 377 scheidet sich bei 830 neben 1,4 Steinsalı, 1,9 Kieserit, 9,3 Carnallit auch $1000 \mathrm{~b}$ $1000:-1,9-6.9,3=134$ Mol. Wasser in I)ampflorm aus, auf 88,2 g. Carnallit alsu $82,3 \mathrm{~g}$ Wasser, und der Bromgehalt der ganzen Ausscheidung ron Sal\% und Wasserdampf in der Carnallitregion ist gleich $\frac{88,9}{182,3}=0,484 \mathrm{mal}$ derjenigen des Carnallits (der kleine Bromgehalt des Steinsalzes bleibt außer Betrachl). Weiterhin hal der reine (arnallit nach den obigen Zahlen einen :0 mal $\left.{ }^{3}\right)$ kleineren (iehalt an Brom als die coexistierende Lösung, die ge-

1) Monatsber. d. d. greul. Ges. 1904, 56, 47-39.

2) Merkmal einer Lrlauge nach feil, vergl. l: ${ }^{\circ} \mathrm{dm} n \mathrm{n}$, in Deulschl. Kalibergbau 26. Carnallit in roncentrierter Iösung zeigte bei derselben Versuchsanordnung nur schr solıwache Lit-Linien, elwas slarkerc eine natürliche lauge aus Salzdelfurlh. line naihere lintersuchung der $\Lambda$ schershobener Lauge wird in der tochn. Hochschule Ilannover ausgefülırt.

3) Das Verhältnis licße sich auch aus der Tabelle S. 338 ableiten. Die daraus hervorgehende /ahl wiirle elwas größer sein als die olige, weil dic natiurliche Lauge slärker chlormağnesiumhaltig ist, als die an Carnallit und $\mathbf{k}$ aliumbalog g nid gesattigte der Tabelle S. 3:8. Das Endresultat wird dadurch nur wenig beeinfußt. 
samte Ausscheidung von Salz und Wasserdampf also den 0,194. Teil des Bromgehalts der Lüsung. Jelzt gilt die Gleichung

$$
a p=(a+d a)(p+d p)-0,194 p d u
$$

in welcher $a$ die Menge Lösung

- da die Ausscheidung von Salz und Wasserdampf

$p$ den Bromgehalt der Lösung darstellt.

$$
\begin{aligned}
-a d p & =0,806 p d a \\
-\int \frac{d p}{p} & =0,806 \int \frac{d a}{a} \\
-\log p & =0,806 \log a+C .
\end{aligned}
$$

Fällt die Menge der Lösung während der Carnallitausscheidung z. B. auf ein Drittel, so ist

oder

$$
\log \frac{p_{1}}{p}=-0,806 \log \frac{2}{3}
$$

Die Schlußausscheidung beträgt

0,6 Steinsalz, 0,3 Kieserit, 1,2 Carnallit, 33 Bischofit, 89 Wasserdampf. Gesamtgewicht $\mathbf{8 7 2 4}$ g, während das Gesamtgewicht der Ausscheidung der Carnallitregion ( + Wasserdampf) 5342 $\mathrm{g}$ beträgt. Wenn die Ausscheidung in der Carnallitregion ganz bis zur Bischofitkrystallisation fortschreitet, ist also doch nur $\frac{\check{\mathbf{3} 342}}{\mathbf{5 3 4 2 + 8 7 2 4}}=0,38$ der Laugenmenge verschwunden. Bei Substitution dieser Zahl in die Formel für den Bromgehalt der Lauge als Funktion der Menge derselben findet man

$$
\begin{aligned}
-\log \frac{p_{2}}{p} & =0,806 \log 0,62 . \\
p_{2} & =1,47 p .
\end{aligned}
$$

Entsprechend würde der Bromgehalt des Carnallits innerhalb der Carnallitregion höchstens auf 1,47 mal den ursprünglichen Betrag steigen können.

Obgleich die natürliche Ablagerung nicht bis zur Bischofitausscheidung vorangeschritten ist, fällt es auf, daß gar keine Zunahme des Bromgehalts in der Carnallitregion vorgefunden wurde. Eine Erklärung dieser Tatsache bildet der Umstand, daß Magnesiumbromidlösungen bei höherer Temperatur Bromwasserstoff abspalten, der von dem atmosphärischen Sauerstoff unter Bromverlust oxydiert werden kann. Dadurch könnte es sich ereignen, daß der Bromgehalt einer natürlichen Mutterlauge nicht über eine bestimmte Grenze hinaus zunimmt.

VI. Überblick über den Bromgehalt der Norddeutschen Kalisalze.

Um neben der Verteilung des Broms im Profil auch diejenige in horizontaler Richtung beurteilen zu können, wurden Salzproben von den Directionen einer Anzahl weit auseinander liegender Bergwerke im deutschen 
Uber d. Krystallisationsschema d. Chloride, Bromide, Jodide v. Natrium usw. $\mathbf{3 8 3}$

Kalisalzgebiet erbeten und mir in liebenswürdigster Weise zur Verfügung gestellt. In Fig. 13 sind die betreflenden Ortschaften durch Kreuze angegeben.

lị̈. 13.

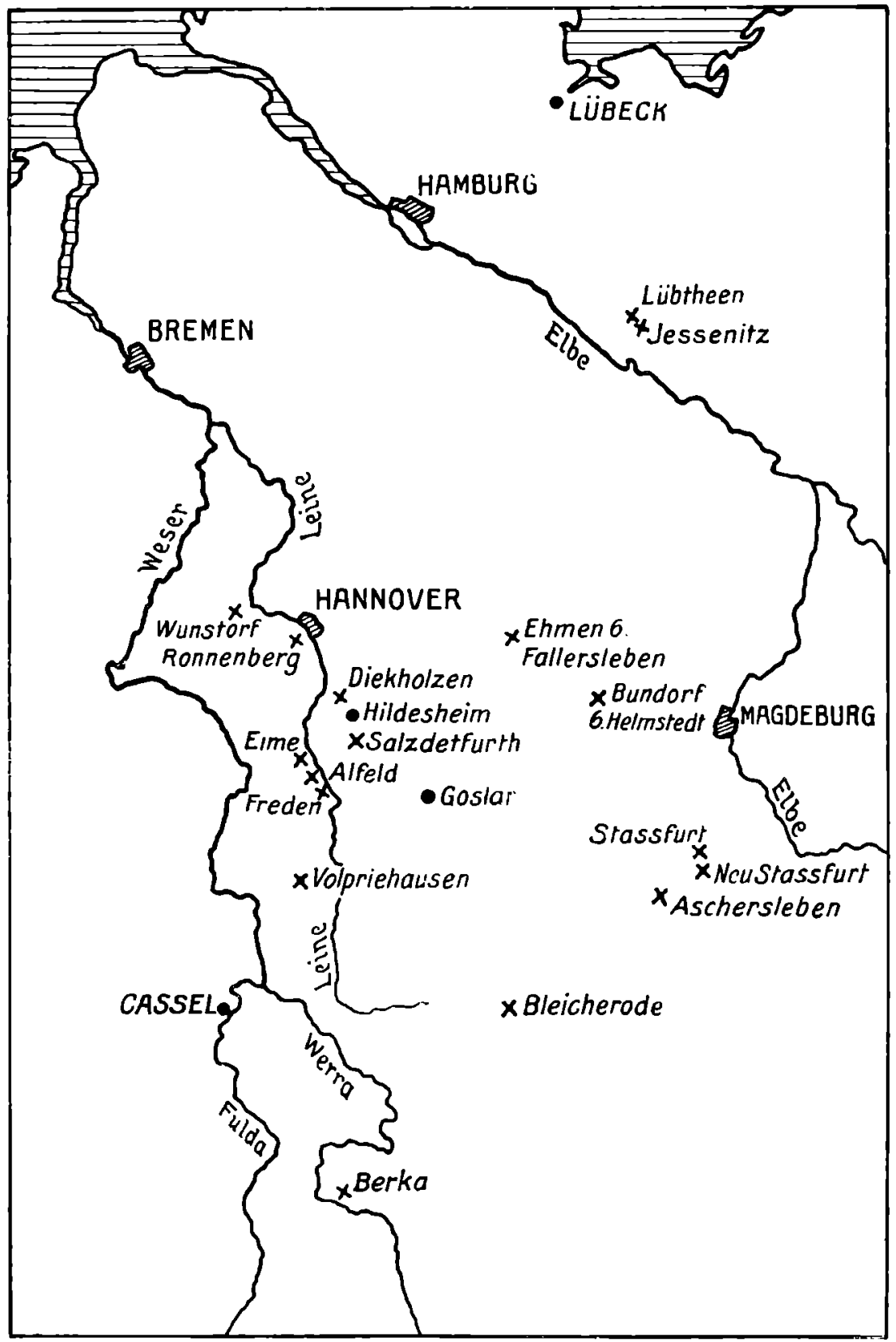

Ubersichtskarte der Werke, von welchen Salzproben untersucht wurden. 
Das Hauptgewicht wurde dabei auf Carnallit gelegt und ferner Sylvin in Sylvinit und Hartsalz untersucht. Auch kamen einige Tachhydrit- und Kainitproben zur Analyse.

Carnallit. Von diesem Mineral wurden im allgemeinen Handstücke studiert, welche verschiedenen Typen angehörten:

1. Geschichteter Carnallit mit Steinsalz und Kieserit: Farbe grau, rosa bis hochrot.

2. Conglomeratischer Carnallit, d. h. Gerölle aus Steinsalz und Kieserit, gelegentlich auch Tongallen, in carnallitischem Bindemittel; Farbe gewöhnlich hochrot.

3. Kieseritfreier hochprozentiger Carnallit, im allgemeinen massig, von weißer oder rosa Farbe.

4. Gelegentliche Bildungen, wie ganz reiner Carnallit, offenbar als Drusen- oder Spaltenmineral; porphyrischer Carnallit mit großen Steinsalzund Sylvinkrystallen und einer Grundmasse aus Carnallit, Steinsalz und Sylvin (Jessenitz in Mecklenburg).

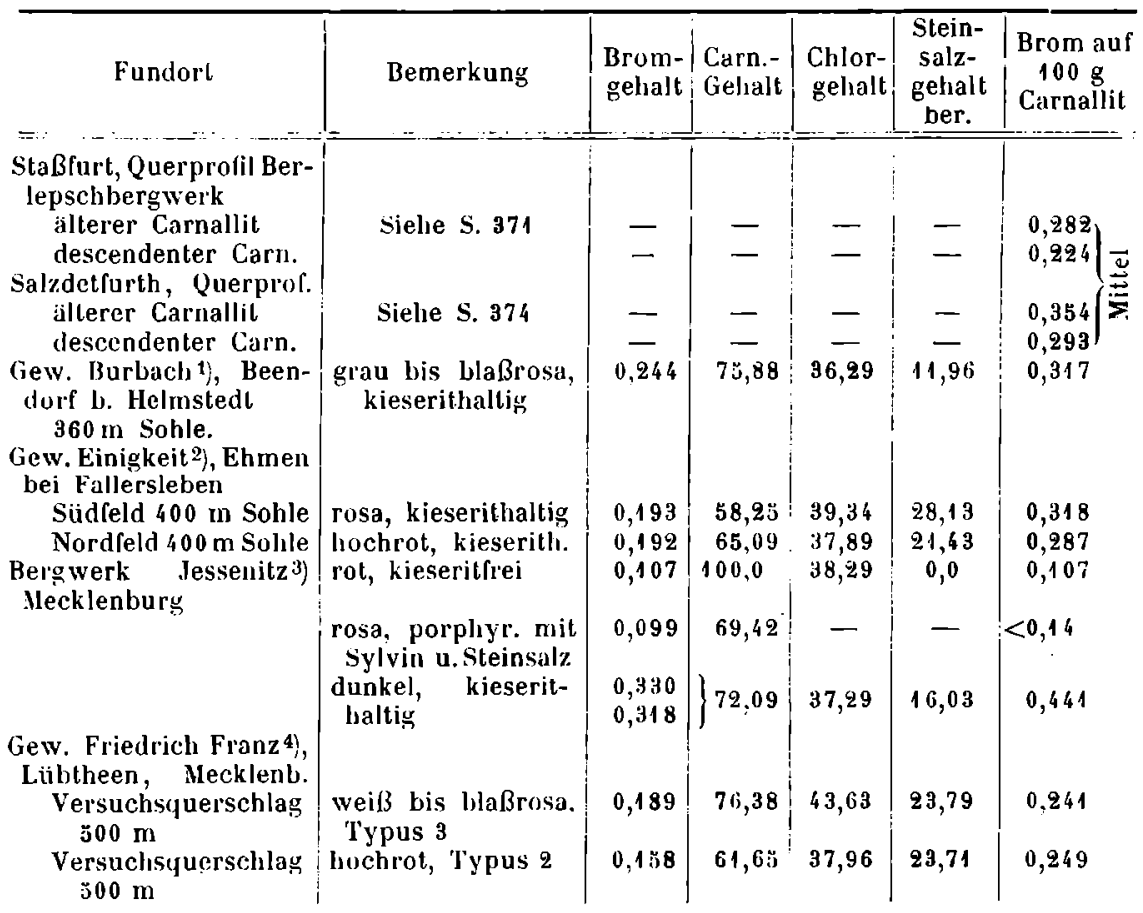

1) Die Proben wurden mir freundlichst überlassen von Herrn Director Simon

2) von Herrn Director Leist,

3) vom Directorium,

4) von Herru Director Bergassessor B a er. 
Über d. Krystallisationsschema d. Chloride, Bromide, Jodide v. Natrium usw. 385

\begin{tabular}{|c|c|c|c|c|c|c|}
\hline Fundort & Bemerkung & $\begin{array}{l}\text { Brom- } \\
\text { gehalt }\end{array}$ & $\begin{array}{l}\text { Carn.- } \\
\text { Gehalt }\end{array}$ & $\begin{array}{l}\text { Chlor- } \\
\text { gehalt }\end{array}$ & $\begin{array}{l}\text { Steins.- } \\
\text { gehalt } \\
\text { ber. }\end{array}$ & $\begin{array}{l}\text { Brom auf } \\
100 \mathrm{~g} \\
\text { Carnallit }\end{array}$ \\
\hline $\begin{array}{l}\text { Gew. Hildesia 1), Diek- } \\
\text { holzen b. Hildesheim } \\
720 \mathrm{~m} \text { Sohle, strei- } \\
\text { chende Strecke } \\
\text { WNW }\end{array}$ & $\begin{array}{l}\text { weiß bis blaßrosa, } \\
\text { Typus } \mathbf{3}\end{array}$ & 0,230 & 99,39 & 40,55 & 8,58 & 0,248 \\
\hline $\begin{array}{l}\text { Gew. Frisch Glück 2), } \\
\text { Eime b. Banteln } \\
\text { Gew. Desdemona 3), Al- } \\
\text { feld (Leine) }\end{array}$ & hochrot, kieserith. & 0,280 & 76,21 & 39,56 & 17,14 & 0,360 \\
\hline $\begin{array}{l}475 \mathrm{~m} \text { Soble, } 350 \mathrm{~m} \\
\text { uördl. v. Schaclite }\end{array}$ & $\begin{array}{l}\text { farblos, klar durcli- } \\
\text { sichtig, ohne Rück- } \\
\text { stand lösl., spaltet } \\
\text { mit wenfg Wasser } \\
K C l \text { ab (Untersch. } \\
\text { von Bischofit) }\end{array}$ & $\begin{array}{l}0,398 \\
0,410\end{array}$ & 99,77 & $98,2: ;$ & 0,1 & 0,404 \\
\hline $\begin{array}{l}690 \mathrm{~m} \text { Solhle West- } \\
\text { feld, 500 m vom } \\
\text { Schachte } \\
\text { Gew. Hohenzollern 4), } \\
\text { Freden (Leine) }\end{array}$ & rosa, kieserithaltig & 0,276 & 89,73 & 37,29 & 4,87 & 0,306 \\
\hline $\begin{array}{l}680 \text { in Sohle, First } 11 \\
\text { So } \\
\text { Königl. Bergwerk Blei- } \\
\text { cherode } 5 \text { ) }\end{array}$ & rosa, Typus 2 & 0,260 & 72,38 & 37,04 & 18,41 & 0,363 \\
\hline $\begin{array}{l}609 \mathrm{~m} \text { Sohle, Schacht- } \\
\text { querschlag Suid }\end{array}$ & hochrol, Typus 1 & 0,225 & 96,49 & 38,50 & 2,59 & 0,233 \\
\hline $\begin{array}{l}609 \mathrm{~m} \text { Sohle, Parallel- } \\
\text { strecke z. Haupt- } \\
\text { querschlag Süd } \\
\text { Gew. Alexandershall 6), }\end{array}$ & hochrot, Typus 2 & 0,250 & 84,65 & 38,90 & 10,73 & 0,292 \\
\hline $\begin{array}{l}\text { Berka a/d. Werra } \\
\text { untere Sohle, Abt. D } \\
\text { Liegendes }\end{array}$ & Mischprobe, weiß, & 0,111 & 32,81 & 45,62 & 42,02 & 0,197 \\
\hline $\begin{array}{c}\text { untere Sohle, A bt. } D_{5}, \\
\text { Hangendes. }\end{array}$ & wenig kieserith. & 0,114 & $\mathbf{5 6 , 7 0}$ & 46,35 & 40,68 & 0,190 \\
\hline $\begin{array}{c}\text { untere Sohle, Abt. C, } \\
\text { mittlere Höhe }\end{array}$ & & 0,129 & 34,75 & $4 \breve{5}, 9 \ddot{~}$ & 41,26 & 0,222 \\
\hline
\end{tabular}

Bei der Verwertung der obigen Zahlen sind die dem Typus 4 angehürigen Proben (100\% \% iger Carnallit und porphyrischer Carnallit von Desdemona bzw. Jessenitz) auszuschalten. Es ergibt sich dann ein zentraler Bezirk, welchem die Werke Beendorf, Ehmen, Salzdetfurth, Eime, Alfeld, Freden angehürcn, wo der Bromgehalt des Carnallits relativ hoch ist; rund herum sind die Zahlen im allgemeinen kleiner. Abgeseben von diesen

1) Die Proben wurden mir freundlichst überlassen von Hrn. Director Dr. Gräfe,

2) von Herrn Director Schneider,

3) von Herrn Director Rusag,

4) vom Directorium; diese und die übrigen Proben aus dem Hannoverschen Bezirke erbielt ich durch die liehenswürdige Vermittlung des Hrn. Civ.-Ing. AndréHannover.

3) von Herm Director Bergrat Zirkler,

6) von Herrn Director Rathke.

Groth, Zcitschrift f. Krystallogr. XI,V. 
kleinen Unterschieden ist der Bromgehalt immerhin recht gleichmäßig im ganzen Kalisalzgebiet, was wohl auf eine im wesentlichen einheitliche Bildung desselben hinweist.

Auf S. 382 wurde schon die Ansicht ausgesprochen, daß ein Teil des Bromids in der Lösung durch atmosphärische Einflüsse zersetzt ist. Daraus läßt sich sogleich folgern, daß descendente, umkrystallisierte Salze, ceteris paribus, einen kleineren Bromgehalt aufweisen müssen als primäre, eben weil die ersteren eine längere Zeit mit der Atmosphäre in Berührung waren in hüchstwahrscheinlich weniger tiefem Wasser.

Nach der von Walther in seiner soeben erschienenen "Geschichte der Erde und des Lebens (1908) nochmals ausgesprochenen Ansicht bildeten sich die deutschen Salzablagerungen, inden das abgeschnürte und eintrocknende Meer im Wüstenklima der oberen Zechsteinzeit sich allmählich zur tiefsten Stelle in Norddeutschland zusammenzog. Bei dieser Auffassung wäre ein höherer Bromgehalt in den tieferen - also der Atmosphäre weniger ausgesetzten - centralen Partien des Meeresbeckens sofort verständlich. Insbesondere ist der geringe Bromgehalt in dem Thüringischen Carnallit (Berka a. $d$. Werra) bezeichnend. Die Ablagerung in diesem Grenzgebiet des Kalisalzbezirkes ist fast horizontal und außerst gleichmäßig über eine weite Strecke, man hat es offenbar mit einer in ihrem ursprünglichen Zustande vorliegenden Ablagerung zu tun.

Eine unerklärliche Ausnahme bei den obigen Zahlen bildet eigentlich nur der dunkle Carnallit von Jessenitz mit Bromgehalt $0,14.1 \%$; es lagen davon aber nur einige nußgroße Stücke ohne nähere Ortsangabe vor. Bei dem sylvinhaltigen Carnallit von Jessenitz war die Berechnung des Broms auf 100 g Carnallit nicht zulässig, weil auch der Sylvin relativ reichlich bromhaltig ist ( $\mathrm{vgl}$. unten); jedenfalls ist der Bromgehalt in dieser Probe sehr gering.

Sylvin. Nach den Krystallisationsergebnissen müßte auch der natürliche Sylvin, besonders weil er aus chlormagnesiumreicher Lösung auskrystallisierte, deutlieh bromhaltig sein, ungefïhr so wie der Carnallit. Die nachfolgenden Analysen erweisen, daß diese Schlußfolgerung zutrellend ist. Bemerkt sei, daß der Sylvin- und Steinsalzgehalt nach der indirekten Methode aus dem ('hlorgehalt berechnet sind. Für den Bromgehalt des Steinsalzes ist nach der Tabelle auf S. $367 \frac{1}{1,4}$ desjenigen des Sylvins angenommen. 
Über d. Krystallisationsschema d. Chloride, Bromide, Jodide v. Natrium usw. 387

\begin{tabular}{|c|c|c|c|c|c|c|}
\hline Fundort & Bemerkung & $\begin{array}{l}\text { Brom- } \\
\text { gehalt }\end{array}$ & $\begin{array}{l}\text { Chlor- } \\
\text { gehalt }\end{array}$ & $\begin{array}{l}\text { Sylvin- } \\
\text { gehalt }\end{array}$ & $\begin{array}{l}\text { Steins.- } \\
\text { gehalt }\end{array}$ & $\begin{array}{l}\text { Brom auf } \\
100 \mathrm{~g} \\
\text { Sylv. ber. }\end{array}$ \\
\hline $\begin{array}{l}\text { Salzdetfurth, desc. Lager } \\
\text { Querprofil } 15-19 \mathrm{~m}\end{array}$ & $\begin{array}{l}\text { weiß, ohne Rück- } \\
\text { stand löslich, kein } \\
\mathrm{SO}_{4} \text {, Spur } \mathrm{MIg}^{-}\end{array}$ & 0,182 & 53,63 & 53,5 & 46,5 & 0,214 \\
\hline $\begin{array}{l}\text { Gew. Burbach, Beendorf } \\
\text { b. Helmstedt } \\
\mathbf{3 6 0 \mathrm { m } \text { Sohle }}\end{array}$ & $\begin{array}{l}\text { weiß mit wenig } \\
\text { blauem steinsalz, } \\
\text { ohne Rückstand } \\
\text { loslich, kein } \mathrm{SO}_{4} \\
\text { und } \mathrm{Mg}\end{array}$ & 0,212 & $\mathbf{3 0 , 2 9}$ & 78,9 & 21,1 & 0,264 \\
\hline $\begin{array}{l}\text { Bergwerk Jessenitz, } \\
\text { Mecklenburg }\end{array}$ & $\begin{array}{l}\text { Sylvinkrystall (mit } \\
\text { Oktaëderflächen), } \\
\text { aus d. erwähnten } \\
\text { porphyr. Carnallit }\end{array}$ & 0,072 & 47,41 & 100 & 一 & 0,072 \\
\hline $\begin{array}{l}\text { Gew. Sigmundshall 1], } \\
\text { Bokeloh b. Wunstorf }\end{array}$ & $\begin{array}{l}\text { wei } \beta, 3 \% \text { doppelt- } \\
\text { brechender Rück- } \\
\text { stand }\end{array}$ & 0,133 & 34,63 & 31,9 & 65,1 & 0,363 \\
\hline $\begin{array}{l}\text { Gew. Ronnenberg }{ }^{2} \text { ) bei } \\
\text { Hannover }\end{array}$ & $\begin{array}{l}\text { wei } B \text {, ohne Rück- } \\
\text { stand löslich, kein } \\
\mathrm{SO}_{4} \text { und } M g\end{array}$ & 0,128 & 53,67 & 53,1 & 46,9 & 0,227 \\
\hline $\begin{array}{l}\text { Gew. Justus 3), Vol- } \\
\text { priehausen }\end{array}$ & $\begin{array}{l}\text { Hartsalz rot, regel- } \\
\text { mäßiges von Salz- } \\
\text { ton überlagerles } \\
\text { Vorkommen }\end{array}$ & $\left\{\begin{array}{l}0,088 \\
0,095\end{array}\right.$ & & $\begin{array}{l}37,70 \\
\text { siehe }\end{array}$ & $\begin{array}{r}27,59 \\
\text { unten }\end{array}$ & 0,233 \\
\hline $\begin{array}{l}\text { Gew. Justus, Volpric- } \\
\text { hausen }\end{array}$ & $\begin{array}{l}\text { IIartsalz grau, un- } \\
\text { regelm. Stockförm. } \\
\text { Vorkommen im } \\
\text { liegend. Steinsalz }\end{array}$ & $\left\{\begin{array}{l}0,108 \\
0,108\end{array}\right.$ & & $\begin{array}{l}36,00 \\
\text { sielie }\end{array}$ & $\begin{array}{l}42,05 \\
\text { unten }\end{array}$ & 0,278 \\
\hline $\begin{array}{l}\text { Königl. Bergw. Bleiche- } \\
\text { rode } \\
609 \text { m Sohle, Eirst I } \\
\text { Ost, } 2 \text { m unter dem } \\
\text { Hangenden }\end{array}$ & $\begin{array}{l}\text { Sylvin aus gesch. } \\
\text { Hartsalz heraus- } \\
\text { präpariert, oline } \\
\text { Rückstand löslicl, } \\
\text { kein } \mathrm{SO}_{4} \text { und } \mathrm{Mg}\end{array}$ & $0,26: 3$ & 47,53 & 100 & - & 0,265 \\
\hline
\end{tabular}

Von den Hartsalzproben aus Volpriehausen wurde seitens der Gewerkschaft Justus freundlichst die Vollanalyse ausgeführıt:

Sylvin

Steinsalz

Kieserit

Lösliches $\mathrm{MgCl}_{2}$

Anhydrit, Tonerde und Eisenglimmer Feuchtigkeit

Summa:

$\begin{array}{cc}\text { Rotes Hartsalz: } & \text { Graues Hartsalz: } \\ 37,70 \% & 36,00 \% \\ 27,59 & 42,05 \\ 27,58 & 8,98 \\ 1,14 & 1,14 \\ 5,31 & 11,22 \\ 0,32 & 0,33 \\ 99,64 \% & 99,72 \%\end{array}$

Die Ursachen, daß der Bromgehalt des Sylvins bis jetzt nicht aufgegefallen ist, sind leicht anzugeben:

1) Die Proben wurden mir bereitwilligst zur Verfügung gestellı von Herrn Director v. d. Hey den.

2) vom Direclorium,

3) von Herrn Director Hönnebeck. 
1. ist der Sylvingehalt des Sylvingesteins nicht so hoch wie die Carnallitführung im Rohcarnallit; Gehalte über $50 \% \mathrm{KCl}$ sind ziemlich selten. Die Bromführung des Gemisches bleibt also bei Hartsalz und Sylvinit relativ gering.

2. liefern die nicht chlormagnesiumhaltigen Salze bei der Verarbeitung keine Endlaugen, in welchen sich das Brom ansammeln würde.

Tachhydrit. Nach der Tabelle auf S. 367 muß der Tachhydrit einen kleineren Bromgehalt aufweisen als der Carnallit, wenn beide aus einer Lüsung mit gleichem Bromgehalt in bezug auf Chlor auskrystallisieren. Die Analysen von zwei Proben aus Neu-Staßfurt bestätigen diese Folgerung.

\begin{tabular}{|c|c|c|c|c|c|c|}
\hline $\mathrm{Nr}$. & Bemerkung & $\begin{array}{l}\text { Bron- } \\
\text { Gehalt }\end{array}$ & $\begin{array}{c}\text { Chlor- } \\
\text { Gehalt } 1 . \\
\text { d. alkohol. } \\
\text { Auszus }\end{array}$ & \begin{tabular}{|} 
Chlor- \\
Gehalt \\
n. d. wäss. \\
Auszug \\
\end{tabular} & $\begin{array}{l}\text { Tach- } \\
\text { hydrit- } \\
\text { Gehalt }\end{array}$ & $\begin{array}{c}\text { Brom } \\
\text { auf } 100 \mathrm{~g} \\
\text { Tach- } \\
\text { hydrit } \\
\end{array}$ \\
\hline 1 & $\begin{array}{l}\text { Vollständig alkohollöslich } \\
\text { bis auf einige wasserklare } \\
\text { Krystallsplitter, welche } \\
\text { auch in Wasser unlöslich } \\
\text { waren; wachsgelb. }\end{array}$ & 0,455 & 40,32 & - & 98,13 & 0,158 \\
\hline 2 & $\begin{array}{c}\text { Knollen, von Boracit um- } \\
\text { und durch wachsen; } \\
\text { wachsgelb. }\end{array}$ & 0,132 & 32,52 & 32,67 & 79,34 & 0,166 \\
\hline
\end{tabular}

Kainit. Es kam eine Kainit-Mischprobe von Neu-Staßfurt zur Untersuchung :
$\mathrm{Br}$
I. $0,030 \%$
II. 0,030
$2,11 \%$

Carnallit (nach dem Alkoholauszug herechnet):

Hieraus geht hervor, daß der Bromgehalt des Kainits sehr gering ist, nur wenig größer als derjenige des Steinsalzes.

\section{C. Über das Fehlen von Jod in den Kalisalzen.}

Auffallenderweise hat man bis jetzt bei der Bromdarstellung aus den Endlaugen der Kalisalzverarbeitung kein Jod vorgefunden. Nur Frank1) teilt mit, daß tatsächlich Jod in dem Brom vorhanden sei, erwähnt aber keine Analysendaten, und Bestätigung hat seine Angabe nicht gefunden.

Im nachfolgenden sind die Versuche mitgeteilt zur Ermittlung, ob Jod ebenso wie Brom die Fähigkeit hat, Chlor in den betreffenden Natrium-, Kalium- und Magnesiumsalzen isomorph zu vertreten (Temperatur 25\%).

Die Analysen von Jodid neben Chlorid wurden ausgeführt nach dem auf Seite 351 angegebenen Verfahren von Friedheim und Meyer.

1) Zeitschr. f. angew. Chem. 1907, 20, 1279. 
Über d. Krystallisationsschema d. Chloride, Bromide, Jodide v. Natrium usw. 389 $K C l-K J$

\begin{tabular}{|c|c|c|c|c|c|c|}
\hline \multirow{2}{*}{$\mathrm{Nr}$. } & \multicolumn{2}{|c|}{ Lösung Gew.-Proc. } & \multicolumn{2}{|c|}{ Krystalle Gew.-Proc. } & \multirow{2}{*}{$C_{L}$} & \multirow{2}{*}{$C_{K}$} \\
\hline & $J$ & $C l$ & $J$ & $C l$ & & \\
\hline$K C l$ & & & & $\begin{array}{l}47,52 \\
47,37\end{array}$ & & \\
\hline 2 & $\begin{array}{l}1, \sqrt{8} \\
\mathbf{3}, \mathbf{2 3}\end{array}$ & $\begin{array}{l}1,90 \\
11,71\end{array}$ & 0,00 & 47,45 & $\begin{array}{l}3,98 \\
7,15\end{array}$ & 0 \\
\hline 3 & 4,57 & 11,27 & 0,00 & 47,56 & 10,19 & $\mathbf{0}$ \\
\hline
\end{tabular}

Carnallit-Jodcarnallit1).

\begin{tabular}{|c|c|c|c|c|c|c|c|c|c|}
\hline \multirow[t]{2}{*}{$\mathrm{Nr}$. } & \multicolumn{2}{|c|}{$\begin{array}{c}\text { Lösung } \\
\text { Gew.-Proc. }\end{array}$} & \multicolumn{2}{|c|}{$\begin{array}{l}\text { Feuchte Kr. } \\
\text { Gew.-Proc. }\end{array}$} & \multirow{2}{*}{$\begin{array}{c}\text { Proc. } \\
\text { Mutterlauge } \\
\text { i. d. Kryst. }\end{array}$} & \multicolumn{2}{|c|}{$\begin{array}{l}\text { Trockne Kr. } \\
\text { Gew.-Proc. }\end{array}$} & \multirow{2}{*}{$C_{L}$} & \multirow{2}{*}{$C_{k r}$} \\
\hline & $J$ & $C l$ & $J$ & $C l$ & & $J$ & $C l$ & & \\
\hline Carnallit & & & & & & -0.07 & $\begin{array}{l}38,25 \\
38,30\end{array}$ & & \\
\hline $\begin{array}{l}1 \\
2\end{array}$ & $\begin{array}{l}5,301 \\
9,21\end{array}$ & $\begin{array}{l}22,2 z \\
18.68\end{array}$ & $\begin{array}{l}0,31 \\
0,47\end{array}$ & $\begin{array}{l}37,18 \\
37,42\end{array}$ & $\begin{array}{l}1,0 \\
4,1\end{array}$ & $\begin{array}{l}0,09 \\
0,09\end{array}$ & $\begin{array}{l}38,30 \\
\mathbf{3 8 , 2 1}\end{array}$ & $\begin{array}{r}0,2 \\
12,1\end{array}$ & 0,04 \\
\hline 3 & 12,03 & 16,73 & 0,65 & 36,74 & 7,9 & $-0,32$ & 38,45 & 16,7 & 0 \\
\hline
\end{tabular}

$\mathrm{MgCl}_{2} \cdot 6 \mathrm{H}_{2} \mathrm{O}-\mathrm{MgJ} \mathrm{J}_{2} \cdot 8 \mathrm{H}_{2} \mathrm{O}$.

\begin{tabular}{|c|c|c|c|c|c|c|c|c|c|}
\hline \multirow[t]{2}{*}{$\mathrm{Nr}$. } & \multicolumn{2}{|c|}{$\begin{array}{c}\text { Lösung } \\
\text { Gew.-Proc. }\end{array}$} & \multicolumn{2}{|c|}{$\begin{array}{l}\text { Feuchte Kr. } \\
\text { Gew.-Proc. }\end{array}$} & \multirow{2}{*}{$\begin{array}{l}\text { Proc. } \\
\text { Mutterlauge } \\
\text { i. d. Kryst. }\end{array}$} & \multicolumn{2}{|c|}{$\begin{array}{l}\text { Trockne Kr. } \\
\text { Gew.-Proc. }\end{array}$} & \multirow[t]{2}{*}{$C_{L}$} & \multirow{2}{*}{$C_{\boldsymbol{K} r}$} \\
\hline & $J$ & $C l$ & $J$ & $C l$ & & $J$ & $C l$ & & \\
\hline $\mathrm{MgCl}_{2} 6 \mathrm{H}_{2} \mathrm{O}$ & 9.93 & 9519 & 0.15 & 33 70 & 193 & -098 & $\begin{array}{l}34,86 \\
35\end{array}$ & 39 & 0 \\
\hline 2 & 5,91 & 23,56 & 0,32 & $\mathbf{3 3 , 7 4}$ & 11,9 & $i-0,43$ & 35,12 & 6,5 & 0 \\
\hline 3 & 8,20 & 22,81 & 0,67 & 93,40 & 14,6 & $-0,63$ & 35,21 & 9,2 & 0 \\
\hline
\end{tabular}

$\mathrm{NaCl}-\mathrm{NaJ}$.

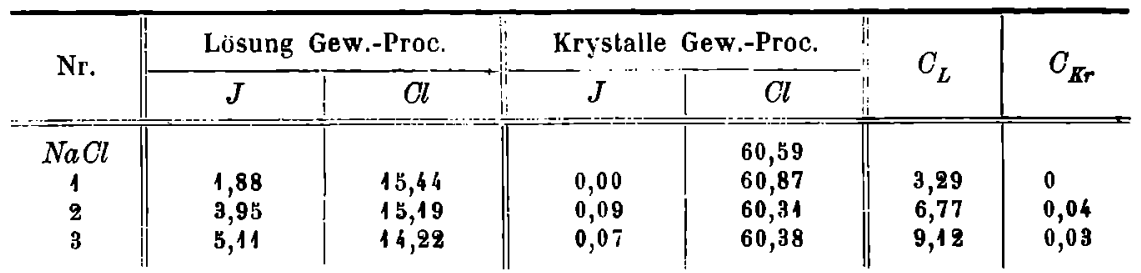

Die kleine Menge Jod, welche in den Chlornatriumkrystallen angetroffen wurde, kann sehr wohl von Einschlüssen herrühren: durch wiederholte Zerreibung und Auswaschen von Krystallen, welche ursprünglich bis $0,5 \mathrm{~mm}$ Kantenlänge zeiglen, konnte der Jodgehalt auf 1 herabgesetzt werden.

1) Ein Jodcarnallit $\mathrm{MgKJ}_{3} .6 \mathrm{H}_{2} \mathrm{O}$ bal de Scbullen (Bull. Soc. Chem. 1900, 23, 158; Ausz. diese Ztschr. 35, 643) darges(ellt und untersucht. Es ist dem Bromcarnallit krystallographisch durcbaus äbnlich. Ich habe seine Beobachlungen bestätigt gefunden. 
T'ach hydrit mit Jodid.

Darstellung der Krystalle, wie für Tachhydrit mit Bromid (S. 365) erwähnt.

\begin{tabular}{|c|c|c|c|c|c|c|c|c|c|}
\hline \multirow[t]{2}{*}{ Nr. } & \multicolumn{2}{|c|}{$\begin{array}{c}\text { Lösung } \\
\text { Gewv-Proc. }\end{array}$} & \multicolumn{2}{|c|}{$\begin{array}{l}\text { Feuclite Kr. } \\
\text { Gew.-Proc. }\end{array}$} & \multirow{2}{*}{$\begin{array}{c}\text { Proc. } \\
\text { Mutterlauge } \\
\text { i. d. Kryst. }\end{array}$} & \multicolumn{2}{|c|}{$\begin{array}{l}\text { Trockne Kr. } \\
\text { Gew.-Proc. }\end{array}$} & \multirow[t]{2}{*}{$C_{L}$} & \multirow[t]{2}{*}{$C_{K r}$} \\
\hline & $J$ & $C l$ & $J$ & $C l$ & & $J$ & $C l$ & & \\
\hline Tachhydrit & 6,06 & 13,89 & 0,39 & 39,96 & 9,5 & $-0,21$ & $\begin{array}{l}41,09 \\
41,20\end{array}$ & $\ddot{5}, 67$ & 0 \\
\hline
\end{tabular}

Kainit mit Jodid.

Die Lösung wurde dargestellt nach van't Hoff') unter Ersetzung von ca. 5\% des Chlorids durch äquivalentes Jodid. Die Krystalle bestanden größtenteils aus Kainit und Chlornatrium und enthielten $0,02 \% \nexists$, also einen innerhalb der Versuchsfehler bleibenden Gehalt. Auch Kainit bildet also mit Jodid keine Mischkrystalle.

Aus den mitgeteilten Zahlen ist der Schluß zu ziehen: Auch wenn das Zechsteinmeer jodidhaltig war, - wie es wohl sehr wahrscheinlich ist - kann kein Jod als Bestandteil der abgelagerten Salze gefunden werden; es müßte sich in Laugeneinschlüssen und in den letzten Resten der Lösung angehäuft haben. Ob grüßere Laugenmengen aus dem ursprünglichen Zechsteinmeer heute noch bestehen, wird aus geologischen Gründen vielfach bezweifelt. Im übrigen ist weiter zu bedenken, daß auch in den Endlaugen sich das Jodid nicht erhalten konntc, wie folgende Versuche zeigen. Es wurden von der schon erwähnten $L i$ haltigen natürlichen Lauge aus $A$ schersleben $500 \mathrm{~g}$ mit $10 \mathrm{~g}$ Kaliumarseniat und $40 \mathrm{ccm}$ Schwefelsäure eine halbe Stunde lang gekocht und das Destillat in Kalilauge aufgefangen. Das letztere wurde eingeengt und mit verdünnter Schwefelsäure, Stïrke und Kaliumnitritlösung versetzt: es zeigte sich keine Spur von Blaufärbung. Jod ist also in dieser Jauge nicht vorhanden. Jetzt wurden $500 \mathrm{~g}$ der Lauge mit $0,1 \% \mathrm{~J}$ in Form von (zuvor von freiem Jod gereinigtem) Magnesiumjodid versetzt, unter Zufügung von Stärke, und die Lösung in einer flachen Schale der Luft ausgesetzt. Innerhalb zweier Stunden war die Lösung dunkelblau gefürbt, diese Farbe verschwand beim Erhitzen und kehrte beim Abkühlen wieder, rührte also von freiem Jod her. Eine Jodlösung aber wird das Jod bald an der Luft verlieren durch Verdunstung. - Die schnelle Zerselzung des Jodids ist wohl eine Folge des milanwesenden Eisens, das an der Luft von Ferro- in Ferriverbindung übergeht $\left.{ }^{2}\right)$. Eine Lösung von $0,1 \% J$ als Magnesiumjodid in reinem Wasser zẹigte die Stärkefärbung auch in mehreren Tagen noch nicht.

1) Oz. Salzabl. I, 70.

a) In der ursprünglichen Lauge war mit Rhodankalium kaum eine Rosafärbung ?u beobachten, das anwesende Eisen liegt darin also nur in Oxydulform vor. 
Über d. Krystallisationsschema d. Chloride, Bromide, Jodide v. Natrium usw. 391

Nach obigem ist anzunehmen, daB Jodide in den Kalisalzablagerungen niemals in irgendwie erheblichen Quantitäten zu erwarten sind.

Während also das Jodid sehr schnell zersetzt sein würde, ist dies mit dem Bromid nach S. 382 und 386 nur teilweise der Fall gewesen; noch stabiler ist das Chlorid. Das von Precht1) im Salzton vorgefundene Magnesiumhydrat ist wohl am einfachsten durch die Zersetzung von Magnesiumjodid und -bromid zu erklären.

Auf Jodat ist in der obigen Auseinandersetzung keine Rücksicht genommen, es ist aber im allgemeinen neben Jodid in den natürlichen Jodvorkommnissen vorhanden. Jodat würde sich bei einer Salzablagerung ebenfalls in der Endlauge anhäufen und wahrscheinlich unzersetzt bleiben. Vielleicht rührt davon der Jodgehalt einiger Flüsse (z. B. Elbe $\left.{ }^{2}\right)$ ) und vieler Salzsolen und Mineralquellen (z.B. Schönebeck ${ }^{3}$ ), Salzungen $\left.{ }^{4}\right)$, Pyrmont $\left.{ }^{5}\right)$ ) her.

SchlieBlich spreche ich den auf S. 384f. erwähnten Herren Bcrgwerksdirectoren, welche mir mit Materialsendungen in freundlichster Weise behilflich waren, meinen herzlichen Dank aus. Insbesondere danke ich ferner den Herren Professor Rinne, Professor Precht-Neu-Staßfurt, Dr. Kubierschky-Eisenach, Bergrat Grübler-Salzdelfurth und Director Ziervogel-Staßfurt auch an dieser Stelle für Unterstützung durch Rat und Tat. - Iie Untersuchung wurde ausgeführt unter Beihilfe aus den Mitteln des neugegründeten Verbandes für die wissenschaflliche Erforschung der Deutschen Kalisalzlagerstätten.
1) Norddcutsche Kaliindustrie 6. Aun., 19.
2) II a a s, Quellenkunde 1895, 133.
3) Gmelin-Kraul 1872, 1, 2, 282 (nach Hermann und Sleinberg).
4) Ebenda (nach Wackenroder).
5) Ebenda (nach Fresenius).

\section{Berichtigungen zu den Figuren.}

Fig. 1, S. 353 lies: resp. « statt *usp.c.

- 8, S. 362. Die Linie $c a$ muß bei $b$ nach abwärts geknickt sein.

- 10, S. 372. Neben 50 crgänze 0,00.

- 13, S. 383 lies: $\bowtie$ Beendorf statt »Bundorf«. 